\title{
From participatory sense-making to language: there and back again
}

\author{
Elena Clare Cuffari • Ezequiel Di Paolo • Hanne De Jaegher
}

Published online: 19 November 2014

C The Author(s) 2014. This article is published with open access at Springerlink.com

\begin{abstract}
The enactive approach to cognition distinctively emphasizes autonomy, adaptivity, agency, meaning, experience, and interaction. Taken together, these principles can provide the new sciences of language with a comprehensive philosophical framework: languaging as adaptive social sense-making. This is a refinement and advancement on Maturana's idea of languaging as a manner of living. Overcoming limitations in Maturana's initial formulation of languaging is one of three motivations for this paper. Another is to give a response to skeptics who challenge enactivism to connect "lower-level" sense-making with "higher-order" sophisticated moves like those commonly ascribed to language. Our primary goal is to contribute a positive story developed from the enactive account of social cognition, participatory sense-making. This concept is put into play in two different philosophical models, which respectively chronicle the logical and ontogenetic development of languaging as a particular form of social agency. Languaging emerges from the interplay of coordination and exploration inherent in the primordial tensions of participatory sense-making between individual and interactive norms; it is a practice that transcends the self-other boundary and enables agents to regulate self and other as well as interaction couplings. Linguistic sense-makers are those who negotiate interactive and internalized ways of metaregulating the moment-to-moment activities of living and cognizing. Sense-makers in enlanguaged environments incorporate sensitivities, roles, and powers into their unique yet intelligible linguistic bodies. We dissolve the problematic dichotomies of high/low,
\end{abstract}

E. C. Cuffari $(\bowtie)$

Department of Philosophy, Worcester State University, Worcester, MA, USA

e-mail: elena.clare.cuffari@gmail.com

E. Di Paolo $\cdot$ H. De Jaegher

IAS-Research Centre for Life, Mind, and Society, Department of Logic and Philosophy of Science, University of the Basque Country (UPV/EHU), Avenida de Tolosa 70, 20018 San Sebastian, Gipuzkoa, Spain

E. Di Paolo $\cdot$ H. De Jaegher

Centre for Computational Neuroscience and Robotics and Centre for Research in Cognitive Science,

School of Life Sciences, Department of Informatics, University of Sussex, Brighton BN1 9QJ, UK

E. Di Paolo

Ikerbasque, Basque Foundation for Science, Bilbao, Spain 
online/offline, and linguistic/nonlinguistic cognition, and we provide new boundary criteria for specifying languaging as a prevalent kind of human social sense-making.

Keywords Participatory sense-making - Social interaction - Linguistic sensitivities and powers · Linguistic bodies · Dialectical expansion model · Wheel of languaging

\section{Introduction}

How do mind and language relate?

Before one can answer this question, one needs to specify what one means by each key term. But to define the key terms is to at least begin to sketch, if not completely presuppose, the relationship between them.

Consider the Chomskyan paradigm of studying the innate, universal human language 'faculty' or 'instinct'. As Chomsky describes his own efforts, "in the technical sense, linguistic theory is mentalistic, since it is concerned with discovering a mental reality underlying actual behavior" $(1965,4)$. In a circular way, a folk theory of mind is presupposed, linguistic data is gathered that supports the idea of universal innate mental faculties, and then an account of the brain is shaped to follow the observations made about linguistic competence.

In contrast, the logic of cognitive linguistics holds that the state of the art knowledge about cognition (concepts, categories, real-world knowledge, and experiences of the world) should inform theoretical and experimental pursuits of language. "Cognitive linguistics sees language as embedded in the overall cognitive capacities of man" (Geeraerts and Cuyckens 2007, 4). The target phenomenon is language as it plays a role in human activities of making sense in and of the world; in other words the research aims ultimately at experience, world, and meaning, rather than at language systems in and of themselves (ibid, 6).

Enaction as a theory of cognition (Varela et al. 1991; Di Paolo 2005; Thompson 2007; Froese and Di Paolo 2011; Di Paolo and Thompson 2014) makes strong and distinctive claims about the nature of mind and human (among other forms of) sensemaking. A theory that makes claims about cognition can be reasonably expected to have implications for a corresponding theory of language. Early 'strains' of enactive thought, notably the work of Maturana and Varela (1980, 1992), indeed included treatments on communication and language rooted in reflections on biological autonomy. For reasons we will return to, these treatments did not make the same impact on language researchers as did, say, the embodied cognitive turn of the 1980s. They remain difficult to work with, although recent theorists of dynamic and distributed approaches to language have picked up Maturana's mantel of 'languaging'. Interestingly, the more recent developments in enactive cognition, which focus on adaptivity and social interaction, have not taken up language as a separate topic, although linguistic activities are listed among other forms of sense-making and social or participatory sense-making (De Jaegher and Di Paolo 2007).

One may wonder as to the absence of a contemporary, comprehensive statement of an enactive view of language. In current socially-oriented cognitive science work one finds both important contributions towards an enactive explanation of and analytical approach to language (for example, Stewart (2010) on writing technologies, Bottineau 
(2010) on varieties of enacting linguistic phenomena, Steffensen (2012) on dialogical systems, Raczaszek-Leonardi (2012) on linguistic symbols as replicable constraints, and Caracciolo (2012) and Popova (forthcoming) on enactively informed accounts of textual interpretation and narratives). At the same time, there is a strong streak of pessimism regarding the possibility that enaction can adequately address such 'higherorder' cognitive faculties (e.g. de Bruin and Kastner 2012; de Bruin and de Haan 2012; Cowley and Nash 2013). In any case, a full story has yet to be told.

So what does enaction claim about cognition, and what do these claims imply about language? To put it first in negative terms, the current paradigm of enactive cognition makes a principled attempt to get by without making theoretical recourse to the notion of mental representations. Likewise enaction theory rejects mind-reading as a central or privileged explanans for how cognition happens and what cognizers do in social interactions. These two moves - setting aside talk of mental representations and mind-reading - already indicate that any enactive account of language must part ways rather sharply with some of the work happening today in pragmatics. For example, consider this passage, which raises a challenge to Neo-Gricean arguments for explaining how interlocutors understand meaning:

Prominent accounts of language use and human communication face something of a dilemma. The dilemma arises because it is assumed (a) that basic communicative situations essentially involve propositional attitude-like states of the participating agents and (b) that competent language users have the conceptual abilities to represent agents as being in such states and make folk-psychological inferences about agents so represented. These assumptions conflict with one of the more robust findings in developmental psychology: that children below the age of 4 years do not possess these abilities. The conflict arises because it is widely agreed in research on language development that children below the age of 3 years are competent language users and communicators in the basic sense. (Breheny 2006, 74)

Enactivists would disagree with the premises (a) and (b); furthermore, there are wellestablished ties between enactive research and developmental psychologists whose work demonstrates the robustness of young children's social cognitive abilities (e.g. Trevarthen 1979; Reddy 2008). Communication is simply not about making inferences about representations; what it is about is something that children of young ages can do as well.

In positive terms, then, enaction theory explains mind as a phenomenon that belongs to life.

For the enactive approach, a system is cognitive when its behavior is governed by the norm of the system's own continued existence and flourishing. Basic cognition, on this view, is not a matter of representing states of affairs but rather of establishing relevance through the need to maintain an identity that is constantly facing the possibility of disintegration. From this perspective, the body is not just the means but also an end of being a cognitive system. To put the point another way, basic cognition is more a matter of adaptive self-regulation in precarious conditions than abstract problem solving. (Di Paolo and Thompson 2014, 73) 
By extension, an enactive approach to languaging will explain it as a kind of sensemaking, i.e. a way that human organisms monitor, evaluate, regulate and organize their existence. An enactive approach will relate languaging to self-produced identities and to the regulation of coupling with environmental domains that support those identities. Languaging will be understood as a way of living. It is this way of living, rather than a theory of mind, that speaking children share with other human interlocutors. What has yet to be made clear is what makes this way of living unique; i.e. what more can we say so that there may be something like enactive studies/analyses of languaging as a meaningfully distinct form of sense-making (better: distinct set of forms of sensemaking) than dancing or looking or X?

The present paper seeks to outline an enactive story and to develop some of its consequences. In the following section we introduce some motivations by detailing some of the recent criticisms of and contributions to a post-Maturanian enactive treatment of language. We then provide a comprehensive outline of our treatment in two explanatory models (see section 3 ). We undertake a dialectical expansion from the basic principles of sense-making and participatory sense-making to their generation of and manifestation in languaging (section 4). Through coordinated and exploratory navigations between individual and interactive sense-makings, social creatures generate recursive and replicable behavioral-organizational conventions. This dialectical unpacking guides us to a specific determination of what makes certain forms of sense-making count as languaging. We define languaging as a form of social agency involving a double regulation of self and interaction that integrates the tensions inherent in dialogical organization and participation genres. The technical meanings of these terms are presented in section 4 . We then offer a model for tracing some of the contingent causal complexities that interact non-linearly in actual instances of languaging (section 5). With this 'wheel of languaging' model we depict how the human style of participatory sense-making becomes increasingly linguistic (on our definition of languaging). Growing up in the environments-ecologies-milieus that people do, we develop sensitivities to certain acts and strategies of coping, and we incorporate the coping practices until they become constitutive of our way of being in the world. We discuss some of the phylogenetic, ontogenetic, and microgenetic levels of this developmental picture. In addition to the two explanatory models, we articulate novel concepts of linguistic sensitivities and powers and linguistic bodies to capture the radical embodiment of languaging as an idiosyncratically incorporated style of participatory sense-making.

Being a linguistic sense-maker, then, is being able to make certain distinctions and organizational moves, for/with one's self and with others, in collaboration with normative and referential world-horizons. We propose that the meanings of languaging acts are consequences in unfolding experience, perception, and action as distinctions are made and interactions or world-transactions are organized (section 6). Being a linguistic sense-maker is not (only) about producing or comprehending texts or verbal utterances. It is more than this, not only because language is 'multimodal', but because languaging is an activity of a signifying and sensitive agent who copes, acts, lives and has its being in a domain constituted by wordings, histories, rules, authorities, articulations, interactions, other people, and the work of other people. In languaging we enact the balance of the idiosyncratic and the in-common, and we generate and experience meaning in the course of so doing. 


\section{Calling for an enactive story of languaging}

The conception of language as a formal representational system accessible only through the right computations learned through parameter fitting (à la Chomsky) cast a long shadow over theoretical linguistics in the twentieth century. Movements in embodiment theory, cognitive linguistics, and situated cognition have profoundly criticized this prevailing model. Yet sometimes those critical of the standard cognitivist view continue to rely on notions borrowed from it (e.g. Damasio 1999; Barsalou 2003; Bergen 2007) or to seek out functionalist fodder for explaining 'high-order' cognitive activities (e.g. Clark 1997; Wheeler 2005; Rowlands 2006). The concerns of recent critics, even if expressed from a much more moderate and perhaps 'embodiment-curious' perspective, therefore repeat a general belief in high-order cognition and language as transcendental phenomena.

Those who carry a torch for functionalist descriptions or larger-than-life explanations of meaning thus wonder how enactivism can treat language. Skeptical placards read "enactivism still has work to do" and "in search of the whole story" (de Bruin and de Haan 2012); "though sense-making is necessary to language, its power is not sufficient to engender even everyday human activity" (Cowley and Nash 2013); "languaging and the unsaid is a serious challenge to enactivism" (Steffensen 2012, 528). According to Cowley and Nash, for example, "concepts like structural coupling and autonomy are not strong enough to throw light on language and human problem solving" (2013, 187). Instead, they prefer to explain problem-solving as relying on "non-local aspects of the ecology" as well as the "observer's mental domain" of a problem-solving participant (ibid.).

Critics worry that enactive accounts of sense-making can merely handle low-level and immediately present or 'concrete' phenomena. "The challenge for enactivism will be to show how a richer notion of coupling can be put to work to explain the development from low-level to high-level social cognition" (de Bruin and de Haan 2012). While the sort of sticky feelings-goo of social cognition-'resonance,' facial mimicry with babies, hand-holding - can have coupling-type explanations, at the end of the day "neither language nor human problem solving reduce to biological sensemaking" (Cowley and Nash 2013, 187).

In response, we insist that the distinctions between "low" and "high" levels, and especially between "online" and "offline" cognition, are necessarily jettisoned in an enactive treatment of language. Such widespread, seemingly intuitive distinctions belie the deep Cartesian roots hiding in everyday language and common-sense from which they originate. These dichotomies are simply different names for the separation between body and mind and those who adopt them are implicitly buying into a dualistic perspective, one that they often claim to criticize. Uncritically assuming this break in the formulation of the question is unlikely to lead to answers that do not perpetuate its inherent dualism.

Enactivism sets aside the misleading metaphor of 'online' and 'offline' cognitive processes that gets deployed in philosophical arguments about social cognition, problemsolving, and linguistic sense-making. Enactivism does not isolate nature and culture, biology and phenomenology. While these may admit of different levels of description, the commitment to a fundamental principle of continuity (cf. Dewey 1938/1991, 30-31) means that coupling and autonomy, as concepts, are not only applicable to 'low-level' sense-making but are equally what we must rely on to explain linguistic sense-making. 
Consider that de Bruin and Kästner, in insisting upon 'decoupled cognition' as a necessary aspect of social cognition (2012), presuppose a scenario in which an individual cognizer is not necessarily in constant co-constitutive relation with her environment. Yet these imagined cases are built on an erroneous conflation of the operational conditions of cognitive processes with the meaning achieved by a cognizer thanks to those processes, and on an erroneously reductive understanding of what it means for something to be 'right there'. It is also crucial to note that the online/offline dichotomy can only be articulated according to the logic of mental representations (Wilson 2002; Barsalou 2003). The end-game of such an account is unavoidably a return to a disembodied, computational-functionalist model of cognition. In contrast, the point of our story is to offer an interpretation of 'living system' and 'niche' that locates meaning, including what may appear to us uncritically as 'internal', 'detached', 'offline' or 'abstract' meaning, in that interaction. ${ }^{1}$

We must not allow our general (and genuine) difficulties and paradoxical experiences of 'being here now' to confuse us: though we may describe our cognitive abilities as transporting us 'beyond' the present moment, it is misguided to attempt to locate the cognitive abilities themselves somewhere beyond the present moment. De Bruin and Kästner's (or de Bruin and de Haan's) fallacy of misplaced concreteness is to associate meaning with coupling. This makes them wonder how we could ever mean what we are not coupled to. Meaning, in contrast, is the relational activity of sense-making, which holistically involves the autonomous agent's adaptive modulation of its own dynamical tendencies and its coupling with the world (Di Paolo 2005, 2009; Thompson 2007). Never in any of the descriptions of sense-making in the enactive literature has meaning been equated with coupling. The coupling between variables and parameters between agent and environment is only one element in the sense-making process, certainly not the bearer of any meaning by itself. Human sense-making involves a range of sensitivities, importantly including linguistic sensitivities, and so the human niche, that which we couple to, is a linguistically mediated and layered or 'enlanguaged' world.

The attempts to show that an enactive story of languaging is doomed before it even starts are, therefore, based on quite misguided interpretations of the theoretical proposals of this approach: viz., a Cartesian split between high and low, online/offline mental function, a narrow reading of the notion of sense-making (one that seems to forget the involvement of the whole organism), and a misunderstanding of basic notions such as the idea of coupling.

There is a positive story to be told about languaging from an enactive perspective. It begins by putting critical distance between earlier enactive explanations and what we here propose.

\section{Our enactive account of languaging: two models}

It is interesting to note that some contemporary scholars (e.g. Kravchenko 2011; Cowley 2011; Bottineau 2010) contribute to a resurgence of Maturana's term "languaging." At the same time, these authors criticize certain features of the enactive

\footnotetext{
${ }^{1}$ See Froese (2012) for a review of the variety of ways that the enactive approach could be capable of accounting for higher-order human cognitive capacities.
} 
view, including the notion of coupling discussed above. It is crucial for us, then, to specify the advancements in our enactive view over the earlier Maturanian one. In contrast to an uncritical adoption of Maturana's ideas, we insist upon a new and different 'enactive' treatment of language.

Maturana's account $(1978,2002,2011)$ is at once deflationary and vague. His definition of languaging casts a broad net: whatever humans do together that meets certain functional criteria of recursive coordination will count. On the other hand, however, Maturana's theory is too thin, because he defines languaging behavior completely in terms of external states of affairs that must obtain. This can be seen in his principle of non-intersecting domains, whereby he holds that

living systems exist in two non-intersecting domains, the domain of their components as molecular autopoietic systems, and in the domain in which they operate as organisms (totalities) in a medium that makes them possible. These two domains do not intersect, the processes that take place in one cannot be reduced to the processes that take place in the other. (Maturana 2002, 15)

The dualistic insistence that a living system's domains do not intersect provokes a worry that the internal processes of organismic self-production and self-maintenance are actually irrelevant to the behavior that takes place in the relational domains (at least constitutively, if not causally). This creates a problem for an embodied account of language, because Maturana's lexicon of specialized terminology pertaining to languaging - e.g. 'coordinations of coordinations' and 'distinctions made within a linguistic domain' (see Maturana and Varela 1992, 210) - is intended to apply only in the external domain. On his view relational behavior occurs only in the consensual domain constituted by repeated interactions between unified agents ("totalities"). The attractive languaging terminology is specifically meant not to speak to the other constitutive domain of organismic life, the domain of internal processes and components (see e.g. Maturana 2011, 147). His descriptions of languaging behavior are strictly third-personal observations made about agents' behaviors in a social interaction. On this view languaging behaviors are indeed social; yet they are 'skin-deep', rather than wholly embodied. Furthermore, nothing can be said about experience or the meaning that these behaviors may have for the agents.

To be clear, we agree with Maturana on the irreducibility of the two domains to each other: e.g. it is incorrect to say that neurons 'decide' or that the amygdala 'emotes'. But irreducibility is poorly described as non-intersection with its connotation of independence (non-intersecting sets do not touch each other, not even at a single point). Even on the strong reading, irreducibility admits that a phenomenon in one domain may count an event in the other as one of its (many) determinants, as long as this transdomain event does not constitute its unique determinant.

The notion of irreducibility leaves the door open for various forms of interaction between domains. Coupling phenomena constrain and enable brain activity and viceversa; they do so without full determination, but often forming inner relations across domains. And the historical dynamics between these constraining relations, underdeveloped in the Maturanian account of non-intersection, allow for the establishment of reliable dependencies across domains: organisms grow into their changing niches because these niches are altered by their constructive activity, often forming relations 
characterized by 'organic', dialectical co-dependence and not merely by non-lethal 'coherence'. Thus patterns of neural activity, bodily action and environmental dynamics, can emerge and reaffirm their relational organizations; we commonly know such patterns as habits, a notion that inevitably spans across the irreducible, but in crucial senses intersecting domains of constitution and relation.

On our reading, then, the most useful point to keep from Maturana is that languaging is living. Human organisms reach a point, conditioned by our living, when we make special descriptions of or distinctions in, our relational domains. This is linguistic behavior. What we want to revise in Maturana's picture precisely concerns the possibility of a connection between our own awareness and regulation of our 'internal' being - our experiences, perspectives, interiority — and the coordinating moves we make and undergo in the relational domain.

Recent developments in enactive theory have sought to overcome the principle of non-intersecting domains as regards other forms of sense-making. Di Paolo's discussions of adaptivity (2005) and extended mind (2009) and Di Paolo et al.'s (2010) discussions of value already indicate a need to relax this principle of non-intersecting domains, and replace it by one of irreducibility. These moves allow the enactive approach to provide an operational definition of sense-making, and thereby a theory of meaning, something that we have shown to be lacking and even avoided in the Maturanian approach to languaging. Those, like the Distributed Language Group, who take up the Maturanian approach, will have to address in some way the question of meaning for participants in the first and second person modes.

In the remainder of this paper, we offer a different story of how "languaging is our manner of living as human beings" (Maturana 2002, 28). In order to talk about language in terms of experience and meaning, and not only externally observable behavior, we propose two models. Both models depict dynamic processes, demonstrating the transformation of sense-making possibilities on individual, interactive, and cultural levels. Both models take up the core qualities of living sense-making: adaptivity, deep change (transformation), a perpetually transcending temporality, and a fundamentally precarious and hence intrinsically normative ontological status. On the basis of these traits, we explain from where meaning and meaning-making practices come.

The first model is dialectical and conceptual. It details how perpetual negotiations of certain primordial tensions in sociality generate culturally shared horizons of normativity. By this logic, languaging emerges as a special kind of social agency, i.e. a particular solution to a certain progression of conceptual problems pertaining to recurrent tensions between individual and interactive levels of sense-making and between codified/constrained and spontaneous styles of sense-making. The second model is diachronic and developmental. It traces human ontogeny as it unfolds in constant coupling to enlanguaged environments. The logic here is one of individuation out of intersubjectivity via the incorporation of certain sensitivities and powers. This incorporation process yields linguistic bodies - bodies that 'know how' to live in language and that reciprocally build and maintain linguistic domains.

The enactive notion of sense-making is central in both models, which depict transformations in ways of sense-making. Yet two distinct models are needed to do two distinct jobs: the first shows how, in purely conceptual terms, the principles of enactivism dictate a definition of languaging as a style of participatory sense-making. 
The second applies and supports this definition of languaging by mapping it on to a plausible human ontogeny in experiential and developmental terms.

\section{The dialectical expansion model: from participatory sense-making to languaging}

The goal of this model is to uncover the logical structure of participatory sense-making by dialectically progressing through a series of conceptually available moves. Performing this expansion leads us to languaging as a style of participatory sensemaking. The starting points for this logical expansion are the core principles of enactivism; it is important to keep these in mind throughout the exercise. First, individuation results from autonomy, i.e., a system that sustains its own identity; second, cognition is the active process of sense-making which is based on norms and values that either originate in the autonomous identity of the agent or are incorporated in some way into it.

In a nutshell, the first point is the enactivist answer to the question of how a cognitive agent is individuated, a question that has otherwise been bypassed by traditional cognitive science. The notion of autonomy is derived from the concept of autopoiesis, or self-production (Varela 1979) and generalized to other domains, not only that of metabolism. Thus an autonomous system is a network of interdependent, recursively enabling processes that sustain themselves under precarious conditions (Di Paolo 2005, 2009; Di Paolo and Thompson 2014; Thompson 2007). The notion of autonomy can thus be applied to an organism, or to a cognitive agent, or even to spontaneous relational patterns that emerge during a sustained social interaction.

The second point is the key enactive move that links the individuation of the cognitive agent with sense-making, or cognition in general (including affect). The precarious nature of an autonomous system requires it to interact with the world and these interactions have intrinsic value (positive, neutral or negative) for the agent itself, for the continuation of its own autonomy, the needful freedom that Hans Jonas discusses (Jonas 1966). In this view, a body is a precarious system under-determined by its internal processes (biology) or external relations (social norms, power), but with a remainder of self-determination that involves the conditioning of body as a whole on itself. The body is constantly buying time for itself, inherently restless due to the unavoidable instability of its material constituents, and inherently in need of relating to the world in terms of significance if its form of life is to be sustained. The outcome of these engagements with the world, moreover, is never guaranteed. Risk is ever-present. ${ }^{2}$

To clarify our terminology, coupling is used in strict dynamical systems terms: a system is coupled to another when some of its parameters depend on the state of variables in the other. Modulation involves a change in the conditions of the coupling (alterations in parameters, constraints and relations between the coupled systems). Regulation is modulation aimed at satisfying some constraint or norm or achieving

\footnotetext{
2 The entailment between precarious, needful identity and normative sense-making is fleshed out in detail using systemic arguments and by introducing the notion of adaptivity (Di Paolo 2005; Thompson 2007). Several implications of these two moves have been explored in the enactive literature (e.g., Di Paolo et al. 2010; Froese and Di Paolo 2011; McGann et al. 2013; Thompson 2007, 2011).
} 
some goal. An agent regulates its coupling with the world following the logic of its own constitution as an autonomous system.

In the dialectical model (Fig. 1), each expansion from a central concept indicates an inner tension, immanent antagonism, conflict or ambiguity inherent in the same concept. Often the tension is one of two kinds: tension between individual and

Fig. 1 A dialectical expansion from participatory sense-making to languaging. Each label is referred to in bold in the main text

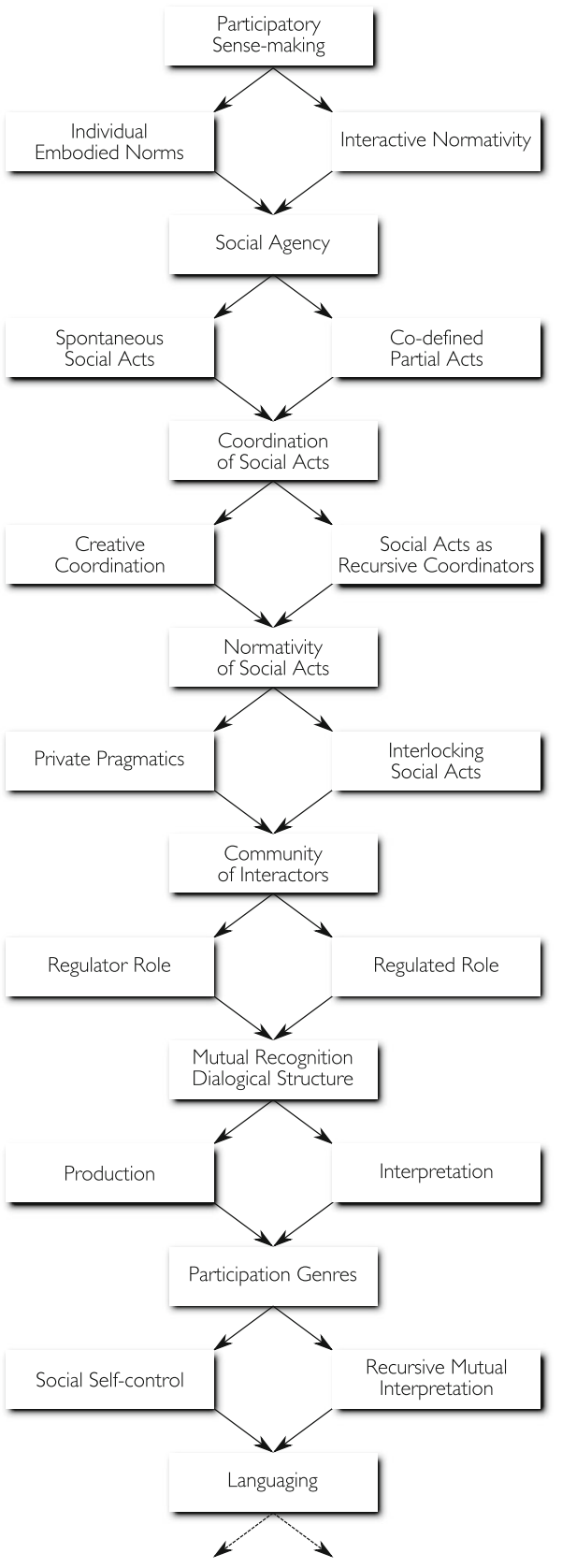


social/interactive levels (or local, private and societal/normative levels), and tension between loose, creative, material, here-and-now, and messy aspects vs. formal, totalizing, a-temporal, rule-based frameworks. The conceptual stage that follows an expansion may work sometimes as a resolution of the tension, other times as a form of integrating the expanded elements by transforming but not necessarily removing their conflict. We emphasize that this dialectical expansion operates at the level of how concepts relate to each other through the selfdeployment of their immanent tensions. It is not meant to be read as a causalhistorical progression.

Each step provides a new conceptual specification of social agency and should be understood as capable of satisfying, integrating or resolving the previous tensions. This does not mean that only this new form will resolve them, but that one way of resolving them is through this new form.

We proceed at each step with the least amount of presuppositions concerning a form of social agency. The analysis starts from the bare concept of participatory sensemaking (De Jaegher and Di Paolo 2007) without any further assumptions. We have two or more autonomous agents, or sense-makers, who by engaging in interaction modulate each other's sense-making and in doing so sustain an autonomous relational domain of coordination while the interaction lasts. They don't do this because they necessarily intend to do it. We need not assume any form of pro-sociality in their individual normative frameworks. We do not even assume that they perceive each other as autonomous agents, much less that they recognize each other as persons yet. As we shall see, some of these crucial aspects of human sociality will come out as resolutions to tensions at specific stages in the development of the dialectical expansion. By avoiding assumptions such as a pro-sociality at the starting conceptual level, the analysis shows the radically social nature of participatory sense-making and how it is able to give rise, through a series of tensions and resolutions, to social agents and eventually, to languaging, without any of these having been inserted in nuce in the head of individual agents from the start.

4.1 The primordial tension of participatory sense-making: embodied individual norms and interactive normativity

We start with the concept of participatory sense-making. It describes the situation in which the sense-making of two or more autonomous agents is mutually modulated as they engage in an interactive encounter. The dynamics of social interaction also form an autonomous self-sustaining identity in the space of coordinated and un-coordinated relational 'moves'. All that is conceptually required for participatory sense-making is the existence of autonomous agents in the enactive sense (Di Paolo 2005, 2009; Thompson 2007) and the possibility of a dynamical coupling between their sensemaking activities in the world such that this coupling acquires, at least for some time, an autonomous dynamics of its own (De Jaegher and Di Paolo 2007). In this basic form, participatory sense-making can happen without sophistications such as the recognition of the other agent as an other. From the perspective of an individual agent, basic participatory sense-making can well be experienced as no more than a special sort of engagement with the world, one where the agent's regulation of coupling may be contingently thwarted, extended, challenged, or changed by the interaction dynamics. 
The two forms of autonomy in participatory sense-making (individual and interactional) establish a primordial tension, one that is managed in increasingly complex ways throughout this story but never fully disappears. It is important to notice that the tension is not between the different intentions of the participants. For that we would need to assume that at this stage participants are able to recognize and understand others as bearing conflicting intentions. The primordial tension is more subtle and pervasive; it is in place even if the other is not present as an other, but as relational patterns that affect my sense-making and are affected by it, such that a social interaction is sustained in time (as in Auvray et al.'s (2009) perceptual crossing experiments where participants collectively resolve a problem without being individually able to distinguish each other from other stimuli ${ }^{3}$ ). To repeat, the primordial tension, describable only because we have defined social interaction in terms of autonomy (De Jaegher and Di Paolo 2007) is, from the beginning, not between individuals, but between an individual and an interactive (social) order.

A single agent acts and makes sense according to her individual embodied norms. These norms, according to enaction, relate to the continuity of various forms of autonomous identity, or forms of life converging in the embodied individual (norms which are biologically, socially, and habitually acquired). However, in an interactive situation these norms may either accompany or be in conflict with the autonomous relational dynamics of the encounter. Sometimes in pursuit of an individual intention, the acts performed by an agent during a social encounter fuel the interaction process, but through their effect on the social coupling they end up frustrating, in apparent paradox, the originally intended goal (e.g., classical narrow corridor example where two people walking in opposite directions get stuck trying to get past each other). There is in the social encounter an interactive normativity, different from individual norms. Regardless of how acts and events are evaluated by the participants, they may or may not contribute to the self-sustaining logic that belongs to the social encounter. An individual participant will sometimes perceive a mismatch between what she intends and what actually happens that in general contrasts with non-interactive situations, and this mismatch, this form of heteronomy from the agent's perspective, has its origins in the double normative dimension of participatory sense-making.

The question is: how is this tension managed? Both synergy and conflict between interactive and individual normativity have implications for individual acts. These acts suffer an analogous doubling of their nature: they are the acts of an individual agent, but they are also moves in an interactive encounter. In the case of conflict, breakdowns occur and the space of opportunities for accommodating these breakdowns is where the participatory labor of (re)creating sense occurs. These are novel sources of frustration that do not occur in solitary existence. In cases of synergy between individual and

\footnotetext{
3 The configuration in the perceptual crossing experiments involves two people interacting through a minimal one-dimensional virtual environment. Each participant is located in a different room. They are allowed to move a computer mouse which controls the position of a "sensor" along a virtual line. When the sensor encounters an object, the participant receives a tap on the finger. All objects encountered produce the same tactile stimulation; some are moving, some are static; some follow the movement of the other participant. The goal is to click on the mouse when a participant thinks or intuits that it is touching the other participant's sensor. Although fraught with ambiguities (such as shadow objects moving identically to the participants' sensors), the task is collectively resolved by the participants who click most frequently on each other sensors even though they cannot individually distinguish reliably between these and other moving objects.
} 
interactive normativity, acts acquire a magic power. They achieve more than I intend to. And conversely, I can achieve what I individually intend to with less, through the coordinated completion of the act by the other. Some acts become inherently social; those acts necessarily seek to coordinate interactive and individual normativity.

The way to balance the struggle between individual evaluation and regulatory agency on the one hand, and interactive dynamics that emerge as several agents both evaluate and seek to regulate the shared domain on the other, is to move to a level of coavailable constraint and significance. Thus throughout its unfolding, the diagram in Fig. 1 depicts the emergence of components of a lifeworld in terms of the levels of normative/referential horizons that sublate each tension and then are presupposed in the next round of interactive negotiations.

\subsection{Social agency: spontaneous social acts and co-defined partial acts}

A single agent, on her own, cannot reliably control the synergy between individual intentions and interactive normativity without terminating the conditions for social interaction (i.e., without overriding the autonomy of other participants). A single agent can only regulate her own coupling to the world in relation to her own individual norms. We have no reason to assume that the credit for sustaining ongoing interactions belongs to individual normativity (as we have said, we do not assume prosociality, although individual values begin to incorporate interactive and social norms as the analysis proceeds). Instead, in order to manage the tension between individual and interactive norms, the regulation of the interactive coupling must involve other participants. Therefore the recovery of interactive breakdowns requires a co-regulation of the interactive coupling. This co-regulation is directed at managing the mismatches between individual intentions of all participants and the interactive dynamics. This is what we call social agency, a specific kind of participatory sense-making whereby the agents not only regulate their own couplings and in doing so influence other agents, but they also jointly regulate the mutual coupling (following norms that pertain to the interactive situation).

Contrast social agency with individual forms of agency, which imply a regulation of the coupling originating in a single agent and aimed at satisfying only individual norms. It is possible for these individual regulations to be affected by the activity of others during participatory sense-making. A mother places a shiny toy in front of an infant to catch her attention. In this way, the mother participates in the infant's sense-making (and the infant participates in the mother's). However, the infant's response to seeing the toy need not involve a co-regulation that jointly achieves anything in response to the mother's action. The infant could conceivably see a toy 'popping-up' in her field of vision while she continues otherwise engaged in interaction with the mother. Social agency, by contrast, begets social acts, i.e., acts involving more than one participant in their execution. Consider the act of giving. This act can be initiated but cannot be completed by one agent alone. Imagine that the mother instead of placing the toy in front of the infant attempts to give it to her, and holds on to it there encouragingly waiting for the infant to start an act that could be the beginning of an acceptance gesture. A tension in the flow of the interaction is created, such that the infant experiences a 'pull' away from her immediate individual engagements that can lead to a co-regulatory move that eventually releases the interactive tension. 
If participants cannot manage the relation between interactive and individual norms, the interactive encounter will eventually stop. Through social agency they adopt one possible strategy to manage this relation: participants attempt to act socially, accepting that individual moves be not just regulated individually but also influenced by others so as to form part of a social act. Since the combination of all the participants' acts following individual norms does not in itself amount to social acts that take into account interactive normativity (remember the narrow corridor example), attempts at co-regulating the interaction have the character of open problems. They are open in the sense that it may not be obvious to the participants what is going wrong when their individual intentions are frustrated in the interaction. Co-regulation thus requires some amount of exploration. Participants may creatively explore fortuitous aspects of the embodied encounter, and its context and dynamics, arriving eventually at spontaneous social acts that achieve the required (but temporary) synergy of individual and interactive norms. (Recall the infant in the example above who completes the act of offering/receiving for the first time.) However, successful social acts also tend to crystallize and be used as the starting point of new searches for conflict resolution. For this, no more than the normal plasticity of individual agents and interactive dynamics need to be assumed. Some co-regulations become well-structured partial acts (offering, receiving). Partial acts sediment not as individual full habits but as a repertoire of equivalent and complementary, unfinished moves. The partial acts performed by different participants count as complementary when they tend to lead to a successful co-regulation of the interaction. Similarly, different partial acts are considered equivalent if any of them contributes to a successful co-regulation of the interaction given a complementary partial act enacted by another participant. Co-defined partial acts, for example the co-defined classes of offering and receiving gestures, therefore relate to other partial acts along these two, paradigmatic and syntagmatic dimensions.

Having at their disposal a structured repertoire of complementary and equivalent partial acts, agents successfully navigating interactive breakdowns need not always rely on a vast unstructured search of possibilities for co-regulation. By contrast, the precarious materiality of interactions and the individual autonomy of embodied agents will always demand some form of creative adjustment of social acts to novel particular situations. The tension between spontaneous social acts and habitual co-defined partial acts, i.e. between the opposing needs for open creativity and patterned regularity, transforms the possibilities of social agency and reshapes the problem of managing the primordial tension through co-regulation. Handling interactive breakdowns will involve, in large part but not always, the coordination of social acts, which is a specific form of social agency.

\subsection{Coordination of social acts: creative and recursive}

A similar tension is repeated at this stage. On the spontaneous end, the creative coordination of social acts involves semi-structured attempts to mutually accommodate partial acts such that their equivalence and complementary relations become redefined, or eventually new classes of partial acts are created. Consider cultural variations in salutation gestures as an example of creative drift of a given partial act (involving similar contexts, e.g., initiation/termination of the encounter, and several 
structural invariants, e.g., body/gaze facing orientation, address, fast time-scale, etc.). For instance, when a Japanese person offers her personal card to you, she holds it with both hands. A Westerner responds to an offer by extending his hand towards the offered object, but this particular gesture is considered disrespectful in Japan (as if one responded with half the body's attention to an offering involving the full body). The solution is to accept the card with both hands. This latter partial act, for the Westerner, was probably part of the same equivalence class as accepting the card with one hand. But now this class is altered as new social norms sub-divide it.

Once a repertoire of partial acts exists, their coordination can be attempted by using the classes already in place. As in the example above, in case of a breakdown, one may try out another equivalent act before giving up on a particular equivalence class (accepting the card, but in a different way). The exploration by participants of equivalent and complementary classes of partial acts can itself be co-regulated by other social acts (imagine the smiling Japanese woman holding fast to her card and looking intently to your other hand in order to gently teach you what a polite person does in these cases). Thus social acts can become recursive regulators of other social acts. They can be used to help coordinate complementary partial acts, or modulate and differentiate equivalent partial acts. Co-regulation in this case becomes a meta-regulation. This is what is referred to as coordination of coordination in Maturana's (1978) approach to languaging. ${ }^{4}$ For instance, achieving the right interpersonal distance during a conversation is a social act, which is normally accomplished through approaching or distancing partial moves. Usually the two opposing factors regulating this act are clarity in hearing each other and discomfort from too much proximity. Whenever normal coregulation fails, for instance, if one of the participants is confined to a bed, it is possible to use social acts to recursively regulate the way the regulation is achieved (a gesture to approach further or to move backwards).

Not only does the recursive use of social acts create a powerful way of handling breakdowns, but in conjunction with the spontaneous, drifting ways of co-adapting social acts, it establishes a normative level expressed in terms of social acts themselves. When a social act is used recursively to modulate other social acts this introduces a double refinement of the primordial tension. On the one hand, the coordinating social act implicitly evaluates the suitability of the partial acts that it coordinates, e.g., whether they fit, or need adjustment (imagine a gesture conveying approval or disapproval). On the other, the regulatory act itself is evaluated but in different terms, in terms of its effectiveness, its clarity, its suitability for mediation (gestures conveying approval or disapproval may be poor mediators if they resemble other gestures or each other too much). Herein lies the tension between the two forms of coordination: the difficulties of always establishing creative coordination from scratch makes participants turn to recursive regulation, which is more structured. But a recursive act that fails to mediate prompts further attempts at creative solutions, including at the level of meta-regulatory gestures. The first aspect of normativity is directly derivative from the original need to handle breakdowns between individual and interactive norms. But the second aspect

\footnotetext{
${ }^{4}$ For Maturana, the notion of languaging essentially reduces to this form of social agency. We think that this is insufficient as important aspects of linguistic behavior remain unspecified, or at the very least too implicit, in this definition as we shall see. These aspects include the resolution of the tensions between idiosyncratic forms of languaging and norms emerging at the community level, and the tensions that arise from attempts to overdominate social interactions that lead to a dialogical structure.
} 
introduces a novel normativity of social acts themselves. Social acts become articulated, codified and evaluated by other social acts, opening a normative, shared horizon within the possibilities of social agency.

\subsection{Normativity of social acts: private and interlocking}

These additional normative elements that use social acts to evaluate other social acts are the result of a history of mutual accommodation between interactive participants. This history is interpersonal and takes the form of a private pragmatics (private in the sense that it belongs to those sharing the same interpersonal history). Private pragmatics accommodates the mutual relation between social acts, idiosyncratically matching their normativity to the material and historical local circumstances. In this situated practice, participants work with an 'anything goes' charity of proto-interpretation: presumably the familiarity from repeated interactions and needs of group life motivate a basic getting-along, an extension of the tacit agreement to co-act pragmatically and to accommodate whatever co-present sense-making is going on. But of course, participants interact outside their in-group too. There is a need that opposes too close an adjustment between particular interactive partners: the need of portability of social acts to other interactions.

Social acts are fluid, full of subtle variations and forms of co-participation. These can be normatively evaluated by means of other social acts as we have just seen. Some of these subtleties, including the novel normativity of social acts, must be adjusted anew with each particular partner. What helps to avoid having to re-construct a full new set of social acts with their own regulatory normativity is if, at least to some extent, partial acts are not only complementary but also interlocking. Interlocking social acts are such that the partial complementary acts that compose them are themselves strongly normative with respect to what they admit as a complement. In other words, they contain in themselves some meta-regulatory elements about what complementary act is expected to follow from another participant. They combine a normal partial act with a meta-regulatory act and so they leave little room for misunderstanding.

For instance, if another agent is getting too close to my personal space, I can gesture with open palms oriented toward the approaching body. This partial act will be successful if the other stops the approach and moves back. But if unsuccessful, the intensification of the same partial act can take the role of the full individual act and the other can in the extreme case be pushed back. This is "interlocking" because implicit in the gesture is a clear indication of what is the expected response that will complete the social act. Such interlocking partial acts are sometimes full individual acts diminished in intensity (as in the example). In such cases, this enhances their portability across interactions between different participants.

Interlocking social acts are in tension with the open-endedness of subtle private pragmatics. They tend to contradict spontaneous, nuanced and idiosyncratic solutions that balance interactive and individual autonomy. But in cases like the example above, they provide useful portability for skillful means of interactive coordination. Thanks to them it is possible to transit between different in-group pragmatics without having to start from scratch.

This particular tension between private pragmatics and portability demonstrates the natural instability and self-deconstruction of some moments of the tension we are 
dialectically expanding. Even as some social acts become sedimented and universalized, and as the effort to accommodate another agent gets 'built in' into the act, the need for that effort never goes away. It may well be the case that our experiences of accommodation and charity in repeated interactions with familiars motivate this effort to engage and coordinate with strangers or those less well known or less frequently engaged.

The tension between creative local accommodation of social acts and their interlocking portability is manifested through recurrent interactions among mobile participants that form a community of interactors. To the extent that historical and material conditions facilitate or demand exchange between groups, initially idiosyncratic forms of social agency can find ways of becoming shared through already established interlocking acts. The latter in turn change historically as particular interactive habits become universal. The interlocking nature of some partial acts is socialized, not necessarily always relying on a structure based on an individual act reduced in intensity, but also on community wide conventions. Social acts eventually acquire a form of closure at the communal level. This is closure in the enactive sense of networks of co-dependence in how social acts relate to each other, such that the meaning of a social act in such a closed network always involves the articulation of other social acts. The open horizon of recursive relations between social acts can now be said to have become a shared social world.

\subsection{Community of interactors: regulator and regulated roles}

Up to this point we have followed the unfolding of forms of social agency, the coregulation of the interactive coupling, which is aimed at managing the relation between individual and interactive norms, i.e., the primordial tension of participatory sensemaking. Individual participants have so far remained symmetrical and indistinct in the sense that we do not assume any pre-established roles in the forms of social agency we have explored. Of course, there may be a conflict between the individual intentions of the participants. Such conflicts have several possibilities: they break down the social interaction (the encounter stops or one of the participants loses their autonomy); without necessarily resolving the conflict, they allow the interaction to continue; or the conflict resolves via successful use of interlocking acts.

But at the communal stage, interpersonal conflicts and their potential resolutions acquire some novel aspects, importantly including roles. As interactors move through a community, they find themselves encountering co-participants with whom they lack a previously achieved interpersonal relation as a product of their own interactive history. Following our minimal presuppositions strategy, however, from my perspective as interactor, social agency is simply a particular form of engagement with the world; it involves other creatures who behave autonomously, but are not yet recognized as persons like myself. I do not yet engage in my individual agency towards them as the bearers of intentions or perspectives; I simply engage with what happen to be the consequences of their acts. Therefore, it is to be expected that when engaging in new encounters (encounters without an interaction history), individual intentions will drive action and participants will attempt to use strongly normative, interlocking social acts. This is not because they wish to dominate others but simply because it is an available, habitual way to hold on to individual intentions by avoiding a misalignment with 
interactive norms. A strongly normative social act tends to guarantee the management of the primordial tension by severely limiting the response options of the newly encountered other.

The overuse of strongly normative, interlocking partial acts is an attempt to move a social interaction under the control of a single agent. If one participant initiates a strongly normative partial act, one that already contains a regulatory layer as to what are its acceptable responses, then this participant is assuming a regulator role. And if the interaction is sustained, then the other participant can only assume a regulated role. The tension can be sustained in time, because to assume the regulated role is not yet to have lost autonomy; it is a role accepted by the regulated participant. Social agency is always strictly a co-regulation of the interactive coupling. However, because of the availability of partial acts with embedded regulatory elements, it is possible for an individual to attempt to regulate the other while still sustaining an element of social agency (requests, orders, demands, etc.), not by forcing the other. Violent acts (those attempting something against the autonomy of the other) in the context of a social interaction were possible all along, but up to this point their effect was always to break off the conditions for the interaction to be properly social by negating the autonomy of one of the participants. Now the possibility emerges of a prolonged inhabiting of the regulator role without breaking down the interaction for some period of time, resulting instead in an asymmetry, which if sustained could potentially become violent in itself within the social interaction. Moreover, the participant in the regulated role is not simply confronting the regulatory attempt of the regulator, but the accepted normativity of a whole community as interlocking social acts become conventional.

As the conflict in this asymmetrical situation becomes sustained in time it can become a threat to the social encounter. The participant playing the regulated role finds her autonomy progressively eroded or puts up a resistance that may break off the interaction. The situation is unstable. A resolution of this potential threat to the social encounter that keeps the advantages of community-sanctioned social acts is reached if participants mutually recognize their own autonomies in Hegelian fashion (see, e.g., Hegel 1807/1976; Honneth 1995; Hyppolite 1969; Ricoeur 2005; Benjamin 1988). In other words, this involves a sensitivity in individual sense-making to what goes wrong in the sustained over-use of a regulator role, namely the other's breaking off of the interaction rather than risking the loss of her autonomy. I cannot fully regulate the other without contradicting my role as a participant in a social interaction. And the reason for this, which I must now appreciate, is that the other is also an autonomous agent. It is worth remarking on this fact because it is relevant for discussions on how we understand other people as being distinct others. Conceptually, in our model to see that the other is an autonomous being (not necessarily a 'person', depending on the stage) involves a new kind of sensitivity to the sense-maker's own effect on the interaction dynamics.

Given that all participants, presumably, have access to the use of strongly normative social acts, at the level of social agency mutual recognition takes the form of trading the regulator and regulated roles over time by adopting a dialogical structure. This allows interactions to remain social and sustained in time through turn organization, while from moment to moment the regulatory burden may be skewed towards the agency of one of the participants. 


\subsection{Mutual recognition in dialogical structure: production and interpretation}

This is a momentous development in the dialectical self-deployment of participatory sense-making, which deserves a much more detailed analysis than we can provide here. Dialogical recognition requires elements such as the turn structure and its various forms of co-regulation, the 'utterance' (a turn-delimited regulatory social act enacted by one of the participants, not necessarily restricted to speech), reciprocity, addressability, and production and reception as conventionalized forms of participatory sense-making.

The dialogical organization and implied mutual recognition of the participants creates a new form of tension. The turn-organization delimits 'utterances,' which must be 'attended to' (listened, observed, etc.). Furthermore, the listener/observer is confronted not simply with a full regulatory social act but with a regulating other, a speaker (gesturer, etc.) who is recognized as an other (subject), who is also a sensemaker. Sense must be made of the other's social act in terms of how it is organized, how long it is likely to last before the turn switches, what its performative aspects are, as well as what it expresses about the one that produces it. We call this interpretive sensemaking. Because the 'listener' is attending both to an 'utterance' and to an other sensemaker, the question "What do you mean?" becomes an issue for the first time. This is the problem of interpretive sense-making: understanding the regulative moves of the other as a signifying other. What is going on with them in this moment of being? What are they experiencing and creating in this moment of sense-making?

The converse side of this problem is the production of the utterance, where a similar set of questions regarding organizational, performative, and expressive aspects is now raised from the side of the speaker/gesturer. As manifestations of the primordial tension of participatory sense-making, production and interpretation of turn-delimited regulatory social acts make opposing demands on the participants. ${ }^{5}$ From the point of view of production, the regulatory act ('utterance') should last as long as required by the producer and this need not be previously known, anticipated or implied early in the production process. The turn-delimited social act should be easily produced and in that sense could well be a monolithic whole, intertwining the performative and expressive aspects without any need for making them explicit or coherent across modalities. From the interpreter's perspective, in contrast, the turn-delimited act of the other should be structured, redundant and easy to 'follow', it should give an indication of its duration early on, and clarify performative and expressive aspects almost as if they were orthogonal dimensions.

Resolving these tensions is often a 'live' problem in everyday dialogues, part of the active sense-making of both producer and receiver. As in earlier steps, it necessitates resolving a coordination problem. This problem can be solved idiosyncratically at first, by the interactive partners accommodating each other's styles (analogous to the private pragmatics at the previous stage). Subsequently these idiosyncratic solutions will pass through the community level socialization (as we have seen before) resulting in what we

\footnotetext{
${ }^{5}$ We have reached a moment in the model that may superficially resemble the standard Saussurean model of speaker-hearer, coder-decoder communication across an abyssal space between two talking heads. This structural resemblance is quite misleading, however, and only appears if one takes it in abstraction from the entire dialectical expansion that we are giving. The distinction between 'producing' and 'receiving' is best seen as a momentary division in labor or distribution of agency, energy and activity within an interactive system. The roles emerge out of and are continually assigned by instances of participatory sense-making.
} 
call participation genres. We introduce this term on the basis of Bakhtin's speech genres, i.e., flexible normative frameworks that pre-structure the organization of utterances in terms of duration, style, expressivity and semantics (Bakhtin 1986). Participation genres (which could include cooking, setting the dinner table, eating together, walking in a group, queuing, finding seats at the theatre, participating in rallies, coordinating labor, playing team sports, etc.) include Bakhtin's speech genres as a subset (salutations, requests, orders, gossip, argument, narration, giving lectures, etc.). They massively pre-coordinate production and interpretation according to context and history. They establish a normative framework from within which turn-delimited regulatory acts can be produced and interpreted. ${ }^{6}$ The social acts framed by participation genres (utterances in the case of speech genres) are structured wholes, with clear contextual indications to the receiver about duration, expected suitable responses, and integrated, yet discernible expressive and performative or semantic aspects. By managing the tensions of production and interpretation, each turn-delimited social act produced by one individual appropriates and selectively perpetuates the normative structuring of the participation genre, which includes, in various forms, a directedness toward the other.

\subsection{Participation genres: social self-control and recursive mutual interpretation}

Interpretive sense-making opens up a new dimension for social agency. A participant's success at establishing some form of regulation through social acts may now fail through misinterpretation. This may happen if the turn-delimited regulatory social act escapes the pre-coordinated normative frame of a participation genre, or plausibly belongs to several genres (i.e., is ambiguous). Suppose that the person in front of you in the supermarket queue drops half of her shopping and you decide to help her with the task of picking up some items still rolling on the floor. In the middle of this process (one participation genre) you realize that this person is a long-lost high-school friend and you start greeting each other and remarking about the odd chance of meeting in such circumstances, asking questions about each other and so on (another participation genre), while you continue picking up groceries. There is potential for confusion here even if one assumes both aspects of the ongoing interaction involve no interpersonal conflict. Should you look her in the eye when she's asking you whether you still live in town or should you kneel down and try to catch the rolling oranges? The most negative outcome in this example would likely be awkwardness, but in other cases it could be misunderstanding, or worse. In cases of ambiguity or misinterpretation, interactors may, like before, continue to attempt to coordinate social acts with others through recursive coordination until the misinterpretation is corrected, and the genre is agreed upon once again (creatively extending the previous one or switching to a new one). This will require recursive mutual interpretation where a participant attempts to make sense of the others' acts and of the others' interpretations of her own responsive acts. (Note that 'interpretation' here is enacted in embodied understanding, not mind-reading.)

It is also possible for the regulator facing misinterpretation of her social acts to attempt to alter her own production, for instance, the relation between its performative and expressive aspects. Different circumstances may lead to this, e.g., when

\footnotetext{
${ }^{6}$ In addition to their direct heritage of Bakhtin, participation genres can be conceptually linked to Goffman's frames, interaction rituals, and forms of talk (Goffman 1967, 1974, 1981) and Kendon's (1990) F-formations.
} 
misinterpretation is pervasive, or when the reciprocity of the dialogical structure breaks down (e.g., unresponsive silence). As an interpreter herself, the regulator can be guided by self-interpretation, which can subsequently lead to attempts at socially regulating herself using the means of dialogical social agency. This form of social self-control is possible because the regulator also plays, at other points in the dialogue, a regulated role and hence knows how to respond to regulatory partial acts, thus acting the parts of the Meadian "I" and "me" (Mead 1934). Hence a single participant can enact a dialogical structure on herself, producing a self-dialogue in search of a way to modulate her expressive and performative acts. We note, however, that this form of social selfregulation does not require the presence of a unified self. Agents at this stage do not necessarily have reflective awareness of fulfilling two different roles.

We would like to emphasize two points about social self-control. 1) To regulate oneself socially is quite a particular form of agency, one that does not directly alter the agent's coupling with the environment according to some incorporated individual norm, but one that imposes on itself an external norm, which is the trace left by the agent's own social act. The sounds of an utterance, or the marks on the ground that I produce to regulate other autonomous agents in dialogue, turn upon me and "externally" regulate my own body. Thus, social control allow us to submit to displaced norms (sometimes going against the body's most immediate concerns). In the here-and-now of the coupling we are able to intend beyond the here-and-now of the organic body. 2) Without having been put in the regulated role by others, or without experiencing the struggle of submitting our own immediate intentions to external regulations, we would never be able to socially regulate ourselves, because to do so implies holding together the regulator and the regulated roles of a dialogue. Our bodies must know submission if they are going to be capable to follow the paths they dictate for themselves (see also Benjamin (1988) on the implications of this point for psychological development).

This is the first appearance of a reflective form of sense-making in the enactive approach.

Social self-control and recursive mutual interpretation are both forms of sophisticated meta-regulation that make social acts quite heavily charged with hermeneutical potentiality. However, the enactment of social self-control in an interactive situation can lead to confusion as attempts to self-regulate get taken as social acts directed at others. Social forms of addressing ("you," or calling someone by their first name during a conversation) solve a similar problem of ambiguity in dialogues involving more than two participants. But they are insufficient in this case, as the confusion is between partial acts directed at the self and partial acts directed at others. In other words, one can attempt to overcome a failed process of mutual interpretation through social selfcontrol, but this very act, in turn can fuel new attempts at mutual interpretation. A (partial) solution of this conflict involves ways of 'shielding' the other from the effect of social regulatory acts directed at oneself by making these acts less overt (e.g., selfcontrol through abbreviated or "private speech" where one plays multiple roles). These self-directed acts, however, are never fully 'internal', even though they may short-cut some aspects of the fully overt 'utterance'. They may motivate gestures, pauses, etc. and thus become again part of the expressive/performative aspects of interaction, in a recursive manner. This self-directedness of socially-structured, mediating, addressable, and regulatory utterances, as has been argued by many following Vygotsky (2012), Mead (1934) and Bakhtin (1986), is also a momentous development (see also 
Volosinov 1986). However, it is often labeled as a form of 'internalization' and considered in its most solitary manifestations, e.g., in mediating individual problemsolving, and not in its more complex interactive original uses and consequences. We call the form of social agency able to negotiate between interactive and self-directed meta-regulation linguistic sense-making, or languaging.

Languaging as the reflexive and reflective negotiating with one's self as with an other is the 'seed' ability out of which abstraction, imagination, and reasoning grow, as one's sense-making powers incorporate the moves, perspectives and expectations of others, and the horizons of significance in which they are embedded. This further suggests that full personhood, with the reflexive consciousness, narrative sense, and responsibilities of a self, co-emerges with full languaging behavior. ${ }^{7}$

It is clear that each of the stages presented here in compact form would deserve further investigation. Also, our final point in this analysis is not to be considered as the end of the story (as the open arrows at the bottom of Fig. 1 suggest). But it seems feasible, in principle, to arrive at the notion of languaging as a dialectical selfdeployment of the notion of participatory sense-making, thus fulfilling our objective of providing an enactive description of what it is to engage in languaging using minimal presuppositions and without involving any concept that would be incompatible with enactive theory. Languaging is a special kind of social agency that emerges from the interplay of coordination and exploration; the outcome of this interplay is a practice that transcends the self-other boundary and enables agents to regulate self and other as well as interaction couplings while incorporating a community-wide normativity at the level of social acts.

\subsubsection{Some notes on symbolization and grammar}

In giving this account we do not take the presence of symbols for granted as an obvious indicator of linguistic behavior (to do so would be putting the cart before the horse). We take symbolization as a graded, emergent phenomenon of iterated interaction coordinations. We suggest that the point of "social acts as recursive coordinators" is an important moment if one were specifically offering a genealogy of symbolization. Another such moment is when the analysis involves the community of interactors and we observe that the open horizon of recursive relations between social acts generates a world. Yet we would like to maintain the possibility that other interactions throughout the dialectical expansion model may be symbolically mediated in some way or involve other aspects of a symbolization process. ${ }^{8}$

\footnotetext{
${ }_{7}$ We here posit a gradedness of self and personhood analogous to Hegel's in "Natural Ethical Life" (Honneth 1995, 23).

${ }^{8}$ Adam Kendon discusses the emergence of linguistic symbols as the sharing of iconic schematizations of acts (as particularly witnessed in linguistic studies of the structure of American Sign Language). Kendon observes that in sign and in speech, "the iconicity... is latently present... it can emerge at any time" (Kendon 2013, 21). The important point then is that constructing "an utterance as a meaningful object, whatever modalities may be used, is always the result of a co-operative adjustment between forms governed by shared formal structures and modes of expression that follow analogic or 'iconic' principles" (ibid; on this issue see also Calbris 2011). This echoes the pattern we present throughout the dialectical expansion model of perpetual negotiation between sedimented and spontaneous, portable and private options for coordination. Joanna RaçzaszekLeonardi's proposal (2012) of linguistic symbols as constraints in a dynamic system is a good example of our understanding of the roles symbols play in linguistic sense-making encounters.
} 
In parallel fashion, traces of grammaticality are observable at earlier points in the diagram as acts are organized according to shared interlocking patterns. Per Linell expresses our view on this well when he writes,

... we do not first have a grammar a priori, and then start building utterances in accordance with it. Instead, we are always immersed in languaging, in and through which we develop habits of using and reusing elements of language and routines of enacting communicative projects through linguistics and other semiotic means. As a result of this continuous process, regularities emerge and rules of linguistic behavior get established and conventionalized. (Linell 2009, p. $56-57)$

The emergence of regularities and the dialectics of conventionalization have clear places in our model. But, additionally, there could be no grammar without first establishing a normative order at the level of social acts, which occurs in our model as recursive regulation involves an evaluation of social acts by other social acts (as appropriate for the current situation or as good or bad mediators). Another key point in our model regarding grammar concerns the resolution of the tensions of 'utterance' production and interpretation, and how the normativity of social acts acquires local character in situated participation genres. The turn-delimited acts become charged with so-called 'turn-constructional units', which organize the turn in a dialogue and are, according Schegloff (1996), one locus at which grammar and interaction intersect.

\subsubsection{Not a historical/causal model}

The stages in the model are meant to be read as conceptual determinations of participatory sense-making. These determinations proceed through the progression between one form of social agency and the inner tensions that it creates and a subsequent form of social agency that (at least partially) resolves or transforms these tensions. The stages are not part of a historical progression, but rather of a conceptual one, as we have stated. ${ }^{9}$ It is perfectly feasible that the historical and material conditions for a new form of social agency are not in place at the right juncture. In such a case, the tensions of the previous stage remain unresolved and the interactions that encounter them simply end there or remain stuck, unable to move past them.

It is possible that some aspects of a later form of social agency may look very much like they could have been in existence independently of prior forms in our model and even before these prior forms have emerged in history. For instance, we postulate that social agency develops into a dialogical form quite 'late' in our expansion model. This may sound odd as aspects of dialogue-like behavior seem to be present in very basic forms of social agency, even those that do not seem to involve the stages we postulate as coming before the dialogical form in our model. This is not a problem for our analysis. It is not the case that the empirical presence of the distinctive properties of the

\footnotetext{
${ }^{9}$ A useful comparison can be drawn with Marx's dialectical analysis of commodities in the first volume of Capital (1867), starting from the tensions between use and exchange value and developing along various forms through socially necessary labor time, money, capital, and class struggle. See also Chris Arthur's (1998) defense of systematic (as opposed to historical) dialectics.
} 
specific form we postulate at given stage must necessarily be a sign that this specific form is already present as such. Turn-taking behavior, for instance, occurs in monogamous tropical birds without (presumably) involving prior stages of recursive forms of co-regulations or communal agreements that we will argue constitute a conceptually prior part of human languaging. This does not mean that tropical birds have adopted the dialogical form of social agency we refer to because the relevant properties (turntaking) do not perform the job of managing the tensions of over-domination, which in our model precede the dialogical stage.

In other words, our conceptual model does not directly address the question of how forms of social agency evolve historically or when they appear first. Nor is it a causal model. When we say that a specific form of social agency resolves or transforms the tensions created at the previous stage, we do not imply that the emergence of the behaviors and capacities that support this new form is due to this function. A given capacity or behavioral pattern corresponding to a form of social agency B may arise in history for many different reasons; it may appear in time quite before the behavioral capacities and patterns that correspond to a form of social agency A which appears prior to B in our conceptual model. In such cases, the behaviors and those capacities of B are simply not yet fulfilling the function we describe in our model, even though they may fulfill different ones.

Having said this, the question of historical origins is indeed one that the present analysis may ultimately contribute to. We are not able in this exercise to show that a form of agency is causally linked to the emergence of a subsequent form. However, we can say at least two things. Firstly, that there is a relation of necessity between a given form of social agency and the internal tensions it creates or reshapes. Secondly, that there is relation of sufficiency between the subsequent form of social agency and the resolution/transformation of those tensions. The historical appearance of behaviors that correspond to one form is contingent with respect to these relations of necessity and sufficiency. A conceptually new form of social agency may rely on behavioral capacities that exist already, or that emerge as a causal result of trying to manage internal tensions at the previous stage, or it may indeed never appear. Any of these could be the case. What is not contingent is that, given its appearance, a form of social agency enters into an intimate relation with pre-existent forms of social agency, and that these relations are the ones we intend to describe in our model. While the historical appearance of a form of social agency is not determined by the others, as it enters into these split relations of necessity and sufficiency described in our model, its historical stability is.

\section{The wheel of languaging: there and back again}

Unlike the neat progression in conceptual space that we have just outlined, phenomena pertaining to our languaging experience and activities do not appear as distinct and prelabeled. The "wheel of languaging" diagram below (Fig. 2) models how participatory sense-making becomes increasingly linguistic for certain real sense-makers, to the point that most human activity is influenced, afforded, and potentially affected by linguistic forms of sense-making. The figure pictures a possible schematization of the always already operative components of languaging, and their relation to each other, as they 

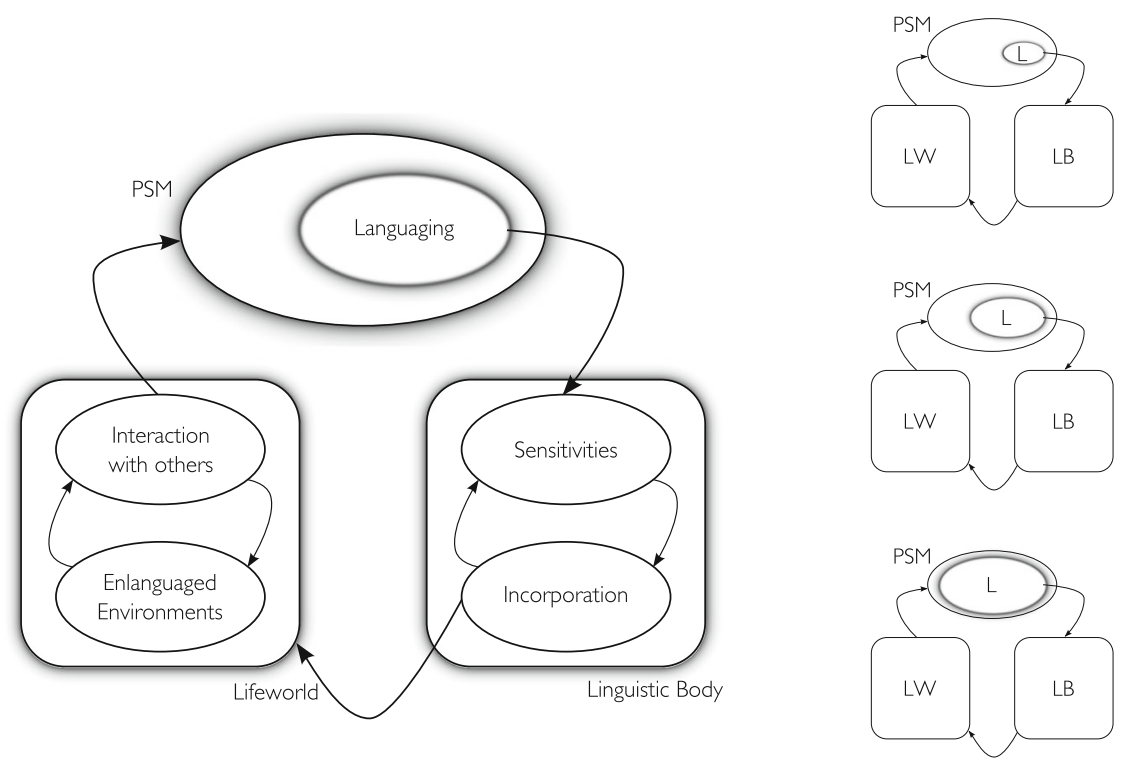

time

Fig. 2 The wheel of languaging. The diagram on the left depicts the all-at-once ongoing relationships of participatory sense-making (PSM), linguistic bodies, and the lifeworld for any given instance of languaging. The external arrows signify a 'referring back to'-e.g., doing language refers to or implies having a linguistically sensitive body — while the internal arrows signify reciprocal affecting - e.g., the mutually reinforcing relationship between cultural horizons (enlanguaged environments) and local encounters (interacting with others). The diagram on the right depicts a human ontogenetic process of being drawn to and on-goingly transforming into an interacting agent whose style of participatory sense-making becomes, via repeated circulation through the wheel, increasingly of the languaging variety. While we do not attempt this here, we could do the same exercise with other timescales, for example phylogenetic or microgenetic tendencies towards languaging

can be unpacked vis-a-vis analysis of embodiment and enculturation offered in the following subsections. ${ }^{10}$

Languaging is a particular style of participatory sense-making. As the dialectical expansion model leaves off, languaging is a special form of social agency, through which linguistic sense-makers negotiate between interactive and self-directed metaregulation of moment-to-moment living and cognizing. Languaging enacts the balance of the idiosyncratic and the in-common by micro-adjusting, with the use of both spontaneity and sedimented resources (acts with built-in regulation, complements,

\footnotetext{
${ }^{10}$ A growing recognition of and attempt to meet this complexity may explain why dynamic and distributed approaches to analyzing language in interaction are gaining ground today. Distributed cognition researchers focus on languaging as 'whole-bodily' interactivity that unfolds on multiple timescales (e.g., Thibault 2011; Steffensen 2013; see Jensen 2013 for a recent review). A review paper of methods in interaction sciences proposes that dynamical systems theory provides the best theoretical framework for integrating various strands of research on human interactions including conversations (Dale et al. 2014). In this section we do not offer prescriptions for analytical methods but rather reflect on what must be the case for such methods to be appropriate to linguistic phenomena. Enacting linguistic activity is an irreducibly complex event. We submit that the enactive notions of sense-making, autonomy, participatory sense-making and interactive autonomy are of value precisely in cross-cutting/grouping/highlighting the features of living that animate language, giving it its form, content, meaning, etc.
} 
and deployment of symbolic structures). Languaging specially enables us to generate and experience content in the course of so doing.

\subsection{Languaging in interaction: introducing sensitivities}

Enactivism proposes a route for naturalizing the notion of sense-making by linking the concept of autonomy (operational closure under precarious conditions) with adaptivity, and by arguing that these phenomena are necessary for a system to regulate (at least some) interactions with its world in terms of the consequences of these interactions for its own continuation (Di Paolo 2005). To be a sense-maker is, in other words, to be actively sensitive to dangerous or beneficial trends in the ongoing coupling with the world. Sense-making thus combines, in nuce and for all forms of life, what for complex minds, like those of animals, can be differentiated into action, perception, and emotion.

To be sensitive to traces and tendencies does not invoke any magical power. To see this, we must understand the temporal thickness of dynamical systems (on this point see also Van Gelder 1999; Varela 1999); this is opposed to the instantaneous and discrete present moment of non-dynamical, computational explanations. This "thick" here-andnow is a way of expressing that "the current situation is not only the states that are actualized, but also the virtual traces and tendencies entailed by them" (Buhrmann et al. 2013, see also Di Paolo 2014). When we combine the intrinsic normativity that emerges in precarious life with the realization that we only live in the present, the conditions for meaning are set. Having a mind, making sense, and transcendent activity are characteristics of life for sensitive, present beings. What we observe on the basis of our dialectical expansion and proposed wheel of languaging is that the particular ways that human life engages these characteristics are inseparably, circularly linked to language.

We define sensitivities as individually embodied habits, or incorporations gained from coupling to visible and invisible registers of the social world, which enable us to perceive and recognize as intelligible various moves of interaction and to respond to these moves in kind. Linguistic sensitivities are completely embodied (in that they are sensory and they are action-informing) and completely enculturated (in that they are a relation to multiple shared registers of normativity and referents). In the next section we discuss what linguistic sense-makers are sensitive to; subsequently we discuss from where these sensitivities come.

\subsection{Sensitivities to the actual and the virtual}

Sense-making for humans implies sensitivities to actual and virtual aspects of what is "out there". We are sensitive to multiple registers and domains of meaning at once: for example, to the means and moves of interacting, as well as the material copresence of our immediate surroundings (sounds, objects, temperature, attitudes, etc.). We are sensitive to the unseen "moreness" of moods and meaning potentials (Gendlin 1997) not immediately before our eyes or beneath our hands and feet. This in turn is possible because we are sensitive to the horizons that open up in social agency and co-regulation (forming a community of interactors), and because our eventual internalization of normative social acts or self-control affords us reflective powers. We also attend to things we can self-present due to memory and imagination. 
In other words, given the kind of worlds we inhabit and the kinds of creatures we are, each person's sense-making is continually but selectively tuned to 'invisible' environments that collectively constitute a lifeworld, except in such situations in which relations to lifeworld break down dramatically as in cases of extreme mental illness or severe trauma.

Transcendence-within-present-sense-making, and sense-making situated within the unseen horizons that provide resources for normativity and referents, can explain what is known in linguistic theory as displacement or displaced reference (Hockett 1960). Displaced reference is commonly described as one of the "design features" that distinguishes human language ability from other animal communication. It is the practice of talking about things that are spatially and/or temporally distant or decontextualized (Meltzoff 1999; Morford and Goldin-Meadow 1997). Indeed, this aspect of our lives in language is significant, and it goes a long way to identifying the seemingly insuperable reach of our cognitive prowess. Yet once again, there is no necessary disruption from sense-making needed to explain referential capacities. Nor do we need an inner/outer dichotomy or a notion of decoupling, once we can see that we are selectively, varyingly, and idiosyncratically sensitive to the "moreness" of the present (Gendlin 1997), thanks to our basic nature as transcenders and to the lifeworld we sustain in our sense-making. This middle-way position is well expressed by Habermas's post-Kantian 'weak naturalism' (Habermas 2003, 17-18).

Our view of sensitivities finds some legacy in several important discussions in twentieth-century treatments of language. In addition to Habermas's pragmatism, we observe an intriguing moment of continuity between our view and that of John McDowell's neo-Kantian treatment of linguistic being-in-the-world. McDowell suggests, "we have what mere animals have, perceptual sensitivity to features of our environment, but we have it in a special form. Our perceptual sensitivity to our environment is taken up into the ambit of the faculty of spontaneity..." $(1996,64)$. As we have told in our expansion story above, spontaneity and local experimentation are always in the mix alongside more stable and codified resources. As our abilities to regulate self and interaction become increasingly sophisticated and dialogic, selfdirected speech arises as an option for us, on the basis of temporal distribution and dialogical relating with others. Thinking and speaking are therefore ready transactions we make as part of getting on in our daily lives, just as is the case with our other sensing engagements. Note that Merleau-Ponty likewise insists that human cognitive capacities - what we call sensitivities - are not added on to more 'basic-level' perceptual faculties $(1963,181)$. Merleau-Ponty rejects any metaphysical weight attributed to an internal/external dichotomy in explaining perception (183).

A neo-Kantian view of intelligence-infused spontaneity, like that expressed in different idioms by Habermas, Merleau-Ponty, and McDowell, supports our idea of linguistic sensitivities. In general terms, human perceptual experience and worldengagement is an integrated whole of embodied interpreting, which we are able to do in virtue of specific integrated skills that are neither purely physical or mechanistic nor purely mental or added-on. Connecting this to participatory sense-making, we observe that our collaborative and personal negotiations alike are constituted by spontaneous responses embedded in horizons of social normativity, horizons that we depend on as being in-common, although importantly, in-common to varying degrees. 
Understanding that linguistic sensitivities consist in the acquired yet spontaneous intelligence of sense-making bodies allows us to identify an interesting philosophical question. Notably this question is not 'how do we talk about the stuff we cannot see right now?' but rather, how is it that we talk about, and out of, different experiences, such that we are understood by others?

What we would like to claim as a preliminary answer to this more interesting philosophical question is that conversing, or making sense together, at bottom involves communing through sensitivities. Linguistic sensitivities as such are what humans have in common, as well as niches, cognitive domains, environments, or worlds that scaffold these sensitivities as we interact in and with them. Affecting each other, "reaching another in his significations" (Merleau-Ponty 1973 139), sharing meaning, requires a precarious balance of difference and common ground.

\subsection{Linguistic bodies: processes of ongoing incorporation}

The scope of one's autonomy, as we know from experience and as we outlined at length in our first model, can be enlarged or reduced through our relations with the world and others (De Jaegher and Froese 2009). Relying on specific engagements with the world can sometimes relax some of the constraints in the internal economy of mutually enabling conditions that constitute the living body (the operationally closed network of enabling relations that defines the autonomous system). These internal relations may drift to the point that a reliable, habitual interactive pattern is no longer an option but a necessity.

This is what we call incorporation: the point when the body can be said to have appropriated a habit, a prosthesis, a tool, a style, etc. Not only does the enactment of the habitual pattern depend on the autonomous body as its source of value and means of effective action, but the body has entrusted some of its internal conditions for operational closure on the regularities of the habit. In this way, the self-sustaining logic of habitual patterns also gets incorporated in the form of non-metabolic values (Di Paolo 2005). Notice then that incorporation is not simply a process of learning a skill where success at learning follows a pre-existing norm, but a process of embodied transformation of the agent to the point that the new form of life incorporates norms that initially made sense only at the level of sustained patterns of behavior (social interactions included). This is why it is so hard to quit smoking. The self-sustaining logic of the habit has been made the body's own, even if over the long term the habit may paradoxically put the body's viability at risk.

What we most notably incorporate into our bodies, as human beings, is a linguistic style of being. This is the reason why we have linguistic sensitivities in the first place and why linguistic events have a direct route to even our physiology, why the complex socio-cultural and interpersonal matrix disclosed by an insult or a compliment can make our blood rush in quite different ways. Our biological being co-evolves with our linguistic and existential being. As an example of physical, cultural, and linguistic co-evolution, consider one proposal that the act of eating in primates (bringing food to the mouth and chewing it) "sets the stage for the development of oral-forelimb manipulatory action systems, and this may explain the co-involvement of hand and mouth in utterance production" (Kendon 2013, 23; see also Gentilucci and Corballis 2006). 
Apart from giving rise to our sensitivities, our incorporation of language is also noticeable in the structuring of our actions, in the way we manage memory, the way we plan and make decisions, and even in "solitary" embodied skills (knitting, assembling flat-packed furniture, etc.) in which complex sequences of "moves" conjugate with each other (cf. Root 1975). This utter enmeshing is one of the reasons it is so difficult to say where language begins or ends (we represent this in Fig. 2 as an ever increasing influence of language as we circulate the wheel of languaging through development).

While we posit incorporation to be a basic perpetual transformative process undergone by all sense-makers coupled to their environments, we also emphasize that innumerable contingencies inform each stage and each turn, making every sensemaker's ontogeny of 'rolling' into languaging unique. Consider differences between human bodies (variations in size, attractiveness, skin color, health, gender traits) and human social environments (geographical region, work setting, education level of caretakers, large or small family, etc.). All of these will have an effect on how this sense-maker becomes sensitive to and powerful in languaging. Although this may be more readily observed in extreme cases of difference, such as autism, Moebius syndrome, other forms of paralysis, or growing up in communities systematically lacking in resources for health and literacy, everyone is somehow marked in their enacting of language. These markings may range from accents to syntactic traces of a native tongue to the specialized vocabularies of university or medical professions to defensive or aggressive conversational practices. New research in linguistics indicates that speakers tap into local institutions of community-generated Gestalt perceptions rather than deploy mental representations of clear-cut phonemes and words (Port 2014). The wheel of languaging model features the circular feedback between social environment, embodiment, and sense-making. This also fits with recent findings about the limited nature of entrainment that takes place in interactions between healthy participants and participants with communication disorders (Borrie and Liss 2014). Histories of frequent interaction breakdowns with others may have a reinforcing effect on socialcommunicative limitations. Borrie and Liss point out that "entrainment deficits in clinical populations [suffering from dysarthria, a production disorder characterized by abnormal speech rhythm] may reveal an important, yet unexplored, source of communication difficulty and demise in quality of life" $(2014,816)$.

Given the enmeshing of language in organic life, it should not be surprising that the precarious aspects of our existence also make themselves felt in languaging. Risk is ever-present in language: the risk of being misunderstood (or left out, 'ex-communicated'), to be sure, but also the risk of directly touching somebody's autonomous being through language. We have seen that this risk is inherent in the use of strongly normative social acts. For this reason, and given differences in how people enact language, enactivism maintains that ethics pertains to language from the very beginning.

It is because our bodies are linguistic (on our definition) that they can acquire expertise through linguistic interaction, and also that they can be accessible to control attempts (by us and others) through their sensitivities and their readiness and capability to structure actions in linguistic formats (orders, questions, supplications, responses, contrasts). Going on a diet, for instance, is in this view something we can only do linguistically, as otherwise, why would our body submit to anything other than its most basic need? Here we note again that Meadian "I-me" structure of linguistic bodies 
entails the incorporation of aspects of the primordial tension in participatory sensemaking itself.

Crucially, the notion of linguistic body that we are introducing is neither a poststructuralist ephemeral body constituted only of moves in a discursive space, nor the standard body frequently taken to ground language in second-wave embodied cognitive science. This latter 'body' is isolated in abstractness and universality (Cuffari and Jensen 2014). According to the basic logic of embodied grounding of language, it is in virtue of individual bodies acquiring similar anatomical and physiological, often particularly neurological, structures that we can share the meaning of words and sentences.

Yet universality is a vexing hinge for the embodied grounding of language. The universal body that would ground language is a selective construction that leaves unaddressed aspects of embodiment that on our account would be pivotal to sensemaking, for instance the precarious autonomy of living bodies, the inevitable yet plastic acquisition of particular histories, idiosyncratic in-the-world perspective and style, and the intercorporeal openness of embodied being. The more recent turn to the brain as the privileged seat of linguistic embodiment (as pointed out by Rohrer 2007 and Froese 2012) in essence offers a revised representationalist account that still must answer the question of how to guarantee that the representations are shared, as well as appropriately deployed. Both intersubjective meaning and the intersubjective encounter as such are left to their own devices. Indeed, the input-output model of activating stored representations, even if these representations are the emergent outcomes of embodied experience, is a version of the conduit metaphor, where language is a code or container for meaning. In the case of simulation semantics, for example, the decoded message is the activated bodily-formatted neural pattern (cf. Bergen 2007; Feldman and Narayanan 2004).

More fundamentally, commonalities, whether they are structural, historical, or cultural, do not guarantee mutual understanding and shared meaning. This is evidenced in everyday life by the spread and frequency of misunderstandings that do not result from perturbations external to communication, such as background noise. The logic of 'pre-installed sharedness' or 'pre-formatting' common to many embodied approaches to language (where interlocutors arrive on scene with the same schematic structures in their cognitive unconsciousness) does not yet equal sharedness in the present, i.e., in the unfolding of real interactions. Something more than identity or universality is needed; shared meaning is in every case a local and joint achievement. Moreover, the achievement of shared meaning is never perfect. It is always partial and temporary. As we have seen in our dialectical model, phenomena such as community socialization or participation genres can facilitate some forms of pre-coordination, but they do not fully eradicate the primordial tension of participatory sense-making, they merely transform it. In each instance, understanding takes place on a spectrum of misunderstanding which is its ever-present background and not its noise-induced exception; we achieve shades of sharing as we on-goingly negotiate meaning with our interlocutors (see also Cuffari 2014). In other words, misunderstandings are the necessary fuel of all languaging. Often at the point where we reach a solid interpersonal agreement not much remains to be said.

Accepting this feature of human sense-making in language renders the motivating problem of grounding language in the body (i.e. the explanation of sharedness) a 
pseudo-problem. In its place, we offer the wheel of languaging as a model of idiosyncratic living bodies that incorporate linguistic sensitivities and hone irreducible styles and powers. This incorporation is in every case its own; differences explain the ubiquitous misunderstandings and also a profound motivation to seek out the nonobvious meaning of the other.

\subsection{Coping and caring in enlanguaged environments}

Linguistic sensitivities are the result of the specific contingencies and ecological coconstitution of our bodily existence in human worlds. This explains not simply that we can make sense of a linguistic event, but a fortiori that we care about it. We care because a linguistic event relates to the very core of how our bodies grow into language as a form of life (Wittgenstein 1953). Without this caring, no amount of sophisticated parsing rules or redundant, self-correcting codes would add up to anything more than meaningless noise.

To offer an illustration of incorporated linguistic sensitivities, it is useful to compare humans with other living beings with whom we also live and make sense. The present that I-and-you-and-the-environment build and transcend in our concerns is an enlanguaged present. Yet as said above, all sense-makers transcend their present; all cognition or sense-making is a result of on-going dynamic coupling, regulating, and adapting. This interactional view opens up the possibility of other living beings in our milieu coming to live a languaging life. Consider the cases of encultured bonobos and gorillas who partially operate in language (see e.g. Savage-Rambaugh et al. 1998; Gillespie-Lynch et al. 2014) or of Chaser the border collie, who comprehends a vocabulary of over 1000 words (Pilley and Reid 2011). Animals that live with humans, in linguistic relational domains, necessarily exist and make sense via coupling with these domains. Species-specific sensitivities to aspects of the domains will of course vary; Chaser does not keep a day calendar, and she is unlikely to have her buttons pressed by Shakespeare. But evidently she is sensitive to some of the same sensory events and patterns as her human companions are in their shared sphere of sense-making.

Noting the differences in linguistic sensitivities between a dog and a human further illuminates ways in which the human milieu is, as we have said (section 5.1), "thick" with more-than-tangible incitements for engagement. Imagine Spot and his walker, Sophie, enjoying a morning outing in a local dog park. Sophie's co-worker from the dog-walking service happens to be there too. She comes up to the pair and, petting Spot, says in a pleasant, sing-song voice, "Sophie is such a terrible dog walker, isn't she? But you are a particularly stupid dog, so it all works out, doesn't it?" Understandably, Sophie is likely to take offense to these utterances if she hears them. Spot, meanwhile, enjoys the tone and attention of the kindly spoken words. Spot does have some or a certain kind of linguistic sensitivity; he knows he is being addressed by the way the human is talking to him. But Sophie's linguistic sensitivities pick up other aspects of the same event. Both Sophie and Spot are afforded a certain kind of sensemaking in their respective here-and-now experiences, but Sophie is sensitive to other registers of significance that are also present and available to her (both as a hearing English speaker and as a specific individual with a workplace interactional history).

While then doing it differently, some animals can, as people do, 'catch on' to words in virtue of the body's "behavior producing power," as Merleau-Ponty suggests (2012, 
425). As humans, we catch on to words because our bodies, being linguistic, are the sorts that can also produce words. Dogs may catch on to words as parts of collaborative social acts that their own behavior then completes. When we understand spoken words as modulations of bodies as beings-in-the-world (ibid.), we no longer need to locate them in a distant sphere or plane, attribute to them a bizarre ethereal ontology, or explain their meaning according to offline internal computations repeated identically in different brains. Rather, the words are patterns available for enacting certain forms of sense-making. Those who experience and enact this kind of sense-making develop and recursively hone sensitivity to it (see Bottineau 2012).

In summary, human embodiment (and in some different degree, other animal embodiments) involves a special kind of autonomy acquired via incorporation of linguistic habits of sense-making. This autonomy relies on processes that are linguistic, as much as other biological and cognitive processes. Otherwise, to repeat, we could not explain where linguistic sensitivities come from. As we saw in comparing the linguistic sensitivities of Spot and Sophie, there are qualitative differences in the degree of complexity of these sensitivities, depending on the sense-maker and the forms of social agency they have incorporated. We include infants and pets as beings with linguistic sensitivities because they live and participate in linguistic domains; linguistic events coordinate the baby's or the dog's participation in the situation. Language is experientially available and integrated into action, even for these agents. There is thus a strong continuity here that parallels the life-mind continuity of sense-making, where transitions do not necessarily have to be smooth (see Jonas 1966; Thompson 2007). Through typical development, however, infants, as suggested on the right of Fig. 2, iterate through the wheel of language with the outcome that most of their participatory engagements become linguistic in style (incorporating the skills required for all the forms of agency described in Fig. 1).

\subsection{Languaging styles: making sense of difference}

In the real flesh-and-blood world of our experiences, others may show up to different degrees or in different ways. Unethically, people may treat each other as means to an end, as sub-persons, as obstacles, or simply with a superficial, cursory degree of engagement and openness. Yet even when we take people only as a circumspectly glimpsed and preferably forgotten 'they', in our contingent reality the other 'agents' who populate and modulate our environments are oftentimes linguistic sense-makers. Thus in most cases our interactions and everyday dealings are not merely of a cognitive problem-solving order (transactions with an environment) but of a moral-cognitive, social order, to borrow Habermas's distinction $(2003,8)$. Problem-solving and coordinating remain motivating impulses to action, but these are inflected with the possibilities of radical accord, disagreement, and transformation that belong to engagements with signifying others, and render these actions as essentially interpretive (as seen after the development of mutual recognition in the dialectical-expansion model). This lifeworld interplay of interactions in enlanguaged environments (Fig. 2) is the condition of meaning-making.

We see misunderstanding as a productive engine for renegotiating meaning and for going further in meaning sharing. This ongoing re-negotiation is at the core of language and its open-endedness. As early and recent writers have noted (Locke 1690; Stewart 2010), we typically understand each other less than we think we do. In daily conversations 
and sense-making exchanges, misunderstanding is prevalent. Sense-making is a process of adjusting, and it is fueled by difference, including the particularities of each person's idiosyncratically sensitive body as we have said (see also Cuffari 2014).

According to enactivism, misunderstandings do not originate solely from imperfectly shared consensual spaces or from external perturbations but are inevitably implied by the autonomy of sense-makers and the autonomous patterns in their interaction. No amount of common ground, homogeneity in conceptual schemes, or conventionalization of sign and symbol can safeguard against misunderstandings. Even the strongest consensus is limited in scope and time as we unpredictably shift individual aims, senses, and concerns spontaneously as well as a result of interaction dynamics. This is, we propose, of the essence in the case of language and explains its vitality and creativity. If this was not the case, if anything worked towards guaranteeing full understanding, we would be talking to machines, not to people. Talking to people, dealing with each other as other linguistic sense-makers, leads both to misunderstanding and to learning and novelty; in short, it is just what keeps the wheel of languaging turning.

\section{Conclusion}

The linguistic event is always a sense-making event, therefore, always already an activity that must happen and be resolved here and now. Pre-existing similarity, participation genres, and shared symbols are parts of this process, but cannot carry it to completion. Participatory sense-making as specially lived out by linguistic sense-makers is thus both conditioned by and practiced in languaging, understood as embodied interpretive interacting, with consequences in the experience of unique interactors and calling for regulatory responses and ethical responsibilities on the parts of those interactors.

From considering an enactive approach to language, we learn that sociality and meaning are present and operative from the very beginning. This stands in contrast to other embodied and ecological approaches to language, where the appearance of meaning on the scene is a later and often unexplained development, or where sociality is secondary and explicitly or implicitly supported only by an individual's pro-social tendencies. In our account, sociality manifests itself as a primordial tension from which different forms of social agency deploy themselves in dialectical fashion. Meaning, understood as relationally achieved consequences in experience and further acting/sensing/experience for a sense-maker, is present in all living engagements. The concept of participatory sense-making makes clear that these consequences (meanings) are jointly afforded and achieved. This indicates finally that linguistic sense-making takes place in an ethical dimension: the autonomy and precarious maintenance of a linguistic body, with the possibilities and needs particular to this form of life, is at stake for all participants in an encounter. 'Doing language' is always a doing-to self and others, an intervening in the conditions, causes and consequences of on-going experiencing and sense-making. As Varela and Maturana make plain, "Every act in language brings forth a world created with others in the act of coexistence which gives rise to what is human. ... This linkage of human to human is, in the final analysis, the groundwork of all ethics as a reflection on the legitimacy of the presence of others" $(1992,247)$.

We take the unavoidable ethical horizon of languaging as a major consequence of our analyses, yet we recognize that this point particularly calls for further work. We speculate that the content generated, or the sense made, in linguistic encounters consists 
at least partially in the modification of the existential, bodily, and emotional (well-)being of participants. ${ }^{11}$ While this claim is in need of further unpacking and justification, it indicates that dialogic ethics would be the new priority in theoretical and empirical investigations of the semantics of human language.

This initial attempt at describing an enactive perspective on languaging - we repeat what we said at the beginning: this is meant to be an outline - demanded the use of two different methods. Our first method, motivated by the multi-layered complexity of linguistic experience, was a conceptual, dialectical expansion of the primordial tension in participatory sense-making. We specified forms of coordination and of social agency from basic to complex. We indicated where and how in this conceptual space one finds utterances, interpretation, normativity, referentiality, and symbolizing.

Complementing this, and attempting to bring back the complexity of experience, the second method provided a series of experiential, developmental and evolutionary argumentation and examples of the particular ways in which linguistic bodies sensitively engage in ongoing human-level sense-making. Pairing these methods yielded three useful core features of languaging: linguistic sensitivities, linguistic bodies, and misunderstanding as the basic motivation for the constant negotiation of meaning in linguistic interactions. These concepts also serve as rejoinders to criticisms discussed in the second section of the paper.

Our account of languaging helps answer a criticism that has been made to the role of embodiment in linguistics, by not tying the concept of embodiment to that of a universal body. Our bodies do not need to play the role of pre-securing sharedness. Rather, they are the result of incorporating linguistic practices. Through this incorporation, they become linguistically sensitive and linguistically powerful; this happens very differently in different personal, historical, and societal contexts. Particular histories of idiosyncratic incorporation, the proliferation of autonomous perspectives, and the temporal openness of sense-making collectively result in unpredictability and inevitable moments of misunderstanding. Without this fundamental friction, there would be no meaning to be made, and we would not be describing language but the hollow operating of perfectly calibrated machines. We think that the mutually constituting relationships in the wheel of languaging, between linguistic bodies and sensitivities and life-world interactions, help us to close the 'cognitive gap' between so-called low-level and high-level cognition. This dichotomy, as well as off-line/on-line, individual/universal, and linguistic/non-linguistic cognition, we dissolve and bypass.

Acknowledgments We owe many thanks to Tom Froese, Thomas Wiben Jensen, Yanna Popova, John Stewart, George Fourlas, Miriam Kyselo, and two anonymous reviewers for their helpful comments on earlier versions of this manuscript. This work is supported by the Marie-Curie Initial Training Network, "TESIS: Towards an Embodied Science of InterSubjectivity" (FP7-PEOPLE-2010-ITN, 264828).

Open Access This article is distributed under the terms of the Creative Commons Attribution License which permits any use, distribution, and reproduction in any medium, provided the original author(s) and the source are credited.

\section{References}

Arthur, C. (1998). Systematic dialectic. Science \& Society, 62(3), 447-459.

${ }^{11}$ For a possibly complimentary line of argumentation, see Hodges et al. 2012. 
Auvray, M., et al. (2009). Perceptual interactions in a minimalist virtual environment. New Ideas in Psychology, 27, 32-47.

Bakhtin, M. M. (1986). Speech genres and other late essays. Austin: University of Texas Press.

Barsalou, L. (2003). Situated simulation in the human conceptual system. Language and Cognitive Processes, $18(5-6), 513-562$.

Benjamin, J. (1988). An outline of intersubjectivity: the development of recognition. Psychoanalytic Psychology, 7(S), 33.

Bergen, B. (2007). Experimental methods for simulation semantics. Methods in cognitive linguistics, 277-301

Borrie, S. A., \& Liss, J. M. (2014). Rhythm as a coordinating device: entrainment with disordered speech. Journal of Speech, Language, and Hearing Research, 57, 815-824. doi:10.1044/2014_JSLHR-S-130149.

Bottineau, D. (2010). Language and enaction. In J. Stewart, O. Gapenne, \& E. A. Di Paolo (Eds.), Enaction. Toward a new paradigm for cognitive science (pp. 267-306). Cambridge: MIT Press.

Bottineau, D. (2012). Remembering voice past: Languaging as an embodied interactive cognitive technique. In Gumanitarniye chteniya RGGU-2012: Teoriya i metodoligiya gumanitarnogo znaniya: Sbornik materialov [Readings in Humanities RSUH-2012: Theory and Methodology of Humanitarian Knowledge: Conference Proceedings] (pp. 194-219).

Breheny, R. (2006). Communication and folk psychology. Mind \& Language, 21(1), 74-107.

Buhrmann, T., Di Paolo, E. A., \& Barandiaran, X. (2013). A dynamical systems account of sensorimotor contingencies. Frontiers in Psychology, 4, 285.

Calbris, G. (2011). Elements of meaning in gesture (Vol. 5). Amsterdam: John Benjamins Publishing.

Caracciolo, M. (2012). Narrative, meaning, interpretation: an enactive approach. Phenomenology and the Cognitive Sciences, 11(3), 367-384.

Chomsky, N. (1965). Aspects of the theory of syntax (No. 11). MIT press.

Clark, A. (1997). Being there: Putting brain, body, and world together again. Cambridge: MIT Press.

Cowley, S. J. (2011). Taking a language stance. Ecological Psychology, 23(3), 185-209.

Cowley, S., \& Nash, L. (2013). Language, interactivity and solution probing: Repetition without repetition. Adaptive Behavior, 21(3), 187-198.

Cuffari, E. (2014). On being mindful about misunderstandings in languaging: Making sense of non-sense as a way to sharing linguistic meaning. In M. Cappuccio \& T. Froese (Eds.), Enactive cognition at the edge of sense-making (pp. 207-237). Basingstoke: Palgrave McMillan.

Cuffari, E., \& Jensen, T. W. (2014). Living bodies: Co-enacting experience. In C. Müller et al. (Eds.), Bodylanguage-communication: An international handbook on multimodality in human interaction (Vol. 2, pp. 2016-2025). Berlin: de Gruyter.

Dale, R., Fusaroli, R., Duran, N., \& Richardson, D. (2014). The self-organization of human interaction. Psychology of Learning and Motivation: Advances in Research and Theory, 59, 43-95.

Damasio, A. (1999). The feeling of what happens. New York: Hartcourt Brace.

de Bruin, L., \& de Haan, S. (2012). Enactivism \& social cognition: In search of the whole story. Journal of Cognitive Semiotics, IV(1), 225-250.

de Bruin, L. C., \& Kastner, L. (2012). Dynamic embodied cognition. Phenomenology and the Cognitive Sciences, 11(4), 541-563.

De Jaegher, H., \& Di Paolo, E. (2007). Participatory sense-making. Phenomenology and the Cognitive Sciences, 6(4), 485-507.

De Jaegher, H., \& Froese, T. (2009). On the role of social interaction in individual agency. Adaptive Behavior, $17(5), 444-460$.

Dewey, J. (1938). Logic: The theory of inquiry. The Later Works, 1953, 1-549.

Di Paolo, E. A. (2005). Autopoiesis, adaptivity, teleology, agency. Phenomenology and the Cognitive Sciences, 4(4), 429-452.

Di Paolo, E. A. (2009). Extended life. Topoi, 28(1), 9-21.

Di Paolo, E. A. (2014). The worldly constituents of perceptual presence. Frontiers in Psychology, 5, 450. doi: 10.3389/fpsyg.2014.00450.

Di Paolo, E. A., \& Thompson, E. (2014). The enactive approach. In L. Shapiro (Ed.), The Routledge handbook of embodied cognition (pp. 68-78). New York: Routledge Press.

Di Paolo, E. A., Rohde, M., \& De Jaegher, H. (2010). Horizons for the enactive mind: Values, social interaction, and play. In J. Stewart, O. Gapenne, \& E. A. Di Paolo (Eds.), Enaction. Toward a new paradigm for cognitive science (pp. 33-87). Cambridge: MIT Press.

Feldman, J., \& Narayanan, S. (2004). Embodied meaning in a neural theory of language. Brain and Language, 89(2), 385-392. 
Froese, T. (2012). From adaptive behavior to human cognition: a review of Enaction. Adaptive Behavior, 20(3), 209-221.

Froese, T., \& Di Paolo, E. A. (2011). The enactive approach: theoretical sketches from cell to society. Pragmatics and Cognition, 19(1), 1-36.

Geeraerts, D., \& Cuyckens, H. (2007). Introducing cognitive linguistics. In D. Geeraerts \& H. Cuyckens (Eds.), The Oxford handbook of cognitive linguistics. Oxford: Oxford University Press.

Gendlin, E. (1997). How philosophy cannot appeal to experience, and how it can. In Gendlin, E., \& Kleinberg-Levin, D. M. (Eds.). Language beyond post-modernism: Language and thinking in Gendlin's philosophy. Evanston: Northwestern University Press.

Gentilucci, M., \& Corballis, M. C. (2006). From manual gesture to speech: a gradual transition. Neuroscience \& Biobehavioral Reviews, 30(7), 949-960.

Gillespie-Lynch, K., Greenfield, P., Lyn, H., \& Savage-Rumbaugh, S. (2014). Gestural and symbolic development among apes and humans: support for a multimodal theory of language evolution. Name: Frontiers in Psychology, 5, 1228.

Goffman, E. (1967). Interaction ritual. London: Penguin.

Goffman, E. (1974). Frame analysis: An essay on the organization of experience. Boston: Northeastern University Press.

Goffman, E. (1981). Forms of talk. Philadelphia: University of Pennsylvania Press.

Habermas, J. (2003). In B. Fultner (Ed.), Truth and justification. Cambridge: MIT Press.

Hegel, G. W. F. (1807/1976). Phenomenology of spirit. (trans: Miller, A. V.). Oxford: Oxford University Press.

Hockett, C. F. (1960). A course in modern linguistics. New York: Macmillan.

Hodges, B. H., Steffensen, S. V., \& Martin, J. E. (2012). Caring, conversing, and realizing values: new directions in language studies. Language Sciences, 34(5), 499-506.

Honneth, A. (1995). The Struggle for Recognition, trans. Joel Anderson. Cambridge, MA: Polity Press.

Hyppolite, J. (1969). Studies on Marx and Hegel. New York: Basic Books, Inc.

Jensen, T. W. (2013). New perspectives on language, cognition, and values. Journal of Multicultural Discourses, (ahead-of-print), 1-8.

Jonas, H. (1966). The phenomenon of life: Toward a philosophical biology. New York: Harper \& Row.

Kendon, A. (1990). Conducting interaction: Patterns of behavior in focused encounters. Cambridge: Cambridge University Press.

Kendon, A. (2013). Exploring the utterances roles of visible bodily action: A personal account. In C. Müller, A. Cienki, E. Fricke, et al. (Eds.), Body-language-communication (Vol. 1). Berlin: De Gruyter Mouton.

Kravchenko, A. (2011). How Humberto Maturana's biology of cognition can revive the language sciences. Constructivist Foundations, 6(3), 352-362.

Linell, P. (2009). Rethinking language, mind, and world dialogically: Interactional and contextual theories of human sense-making. Charlotte: Information Age Publishing.

Locke, J. (1690). An essay concerning human understanding, 1. The Electronic Classics Series, Jim Manis, Editor. Hazleton PA.

Marx, K. (1867/1976). Capital: A critique of political economy. Volume I, London: Penguin Books.

Maturana, H. R. (1978). Biology of language: The epistemology of reality. Psychology and Biology of Language and Thought, 27-63.

Maturana, H. (2002). Autopoiesis, structural coupling and cognition: a history of these and other notions in the biology of cognition. Cybernetics \& Human Knowing, 9(3-4), 3-4.

Maturana, H. (2011). Ultrastability... autopoiesis? Reflective response to Tom Froese and John Stewart. Cybernetics \& Human Knowing, 18(1-2), 1-2.

Maturana, H. R., \& Varela, F. J. (1980). Autopoiesis and cognition: The realization of the living. Dordrecht: D. Reidel Pub. Co.

Maturana, H., \& Varela, F. (1992). The tree of knowledge. Boston: Shambhala.

McDowell, J. H. (1996). Mind and world: With a new introduction. Cambridge: Harvard University Press.

McGann, M., De Jaegher, H., \& Di Paolo, E. (2013). Enaction and psychology. Review of General Psychology, 17(2), 203.

Mead, G. H. (1934). Mind, self \& society from the standpoint of a social behaviorist. Chicago: University of Chicago Press.

Meltzoff, A. N. (1999). Origins of theory of mind, cognition and communication. Journal of Communication Disorders, 32(4), 251-269.

Merleau-Ponty, M. (1963). The structure of behavior. Boston: Beacon.

Merleau-Ponty, M. (1973). The prose of the world. Evanston: Northwestern University Press.

Merleau-Ponty, M. (2012). Phenomenology of perception (trans: Landes, D. A.). Abingdon: Routledge. 
Morford, J. P., \& Goldin-Meadow, S. (1997). From here and now to there and then: The development of displaced reference in homesign and English. Child Development, 68(3), 420-435.

Pilley, J. W., \& Reid, A. K. (2011). Border collie comprehends object names as verbal referents. Behavioural Processes, 86(2), 184-195. doi:10.1016/j.beproc.2010.11.007.

Popova, Y. B. (forthcoming). Stories, meaning, experience: Narrativity and enaction. Taylor and Francis.

Port, R. (2014). Language as a social institution and understanding as prediction. Finding common ground: Social, ecological and cognitive perspectives on language use. University of Connecticut, June 12-14 2014. Presentation.

Rączaszek-Leonardi, J. (2012). Language as a system of replicable constraints. In Laws, Language and Life (pp. 295-333). Netherlands: Springer.

Reddy, V. (2008). How infants know minds. London: Harvard University Press.

Ricoeur, P. (2005). The course of recognition. Cambridge: Harvard University Press.

Rohrer, T. (2007). Embodiment and experientialism. Oxford handbook of cognitive linguistics, 25-47.

Root, M. D. (1975). Language, rules and complex behavior. In K. Gunderson (Ed.), Language, mind and knowledge (pp. 321-343). Minneapolis: University of Minnesota Press.

Rowlands, M. (2006). Body language: Representing in action. Cambridge: MIT Press.

Savage-Rambaugh, S., Shanker, S. G., \& Talbot, T. (1998). Apes, language, and the human mind. New York: Oxford University Press.

Schegloff, E. A. (1996). Turn organization: One intersection of grammar and interaction. In E. Ochs, E. A. Schegloff, \& S. A. Thompson (Eds.), Interaction and grammar (pp. 52-133). Cambridge: Cambridge University Press.

Steffensen, S. V. (2012). Care and conversing in dialogical systems. LSC Language Sciences, 34(5), 513-531.

Steffensen, S. V. (2013). Human interactivity: problem-solving, solution-probing and verbal patterns in the wild. In Cognition Beyond the Brain (pp. 195-221). London: Springer.

Stewart, J. (2010). Foundational issues in enaction as a paradigm for cognitive science: From the origin of life to consciousness and writing. In J. Stewart, O. Gapenne, \& E. A. Di Paolo (Eds.), Enaction. Toward a new paradigm for cognitive science (pp. 1-31). Cambridge: MIT Press.

Thibault, P. J. (2011). First-order languaging dynamics and second-order language: the distributed language view. Ecological Psychology, 23(3), 210-245.

Thompson, E. (2007). Mind in life: Biology, phenomenology, and the sciences of mind. London: Harvard University Press.

Thompson, E. (2011). Philosophy: life emergent. Nature, 480(7377), 318.

Trevarthen, C. (1979). Communication and cooperation in early infancy: A description of primary intersubjectivity. Before speech: The beginning of interpersonal communication, 321-347.

Van Gelder, T. J. (1999). Wooden iron? Husserlian phenomenology meets cognitive science. In J. Petitot et al. (Eds.), Naturalizing phenomenology (pp. 245-265). Standford: Standford University Press.

Varela, F. J. (1979). Principles of biological autonomy (pp. 14-23). New York: North Holland.

Varela, F. J. (1999). The specious present: A neurophenomenology of time consciousness. In J. Petitot et al. (Eds.), Naturalizing phenomenology (pp. 266-314). Standford: Standford University Press.

Varela, F. J., Thompson, E., \& Rosch, E. (1991). The embodied mind: Cognitive science and human experience. Cambridge: MIT Press.

Volosinov, V. N. (1986). Marxism and the philosophy of language. (trans: Matejka, L. \& Titunik, I. R.). Cambridge, Mass: Harvard University Press.

Vygotsky, L. S. (2012). Thought and language. Cambridge: MIT Press.

Wheeler, M. (2005). Reconstructing the cognitive world: The next step. Cambridge: MIT Press.

Wilson, M. (2002). Six views of embodied cognition. Psychonomic Bulletin \& Review, 9(4), 625-636.

Wittgenstein, L. (1953). Philosophical investigations. (trans: Anscombe, G. E. M.). Oxford: Basil Blackwells. 